Cite as: A. J. Greaney et al., Sci. Transl. Med. 10.1126/scitranslmed.abi9915 (2021).

\title{
Antibodies elicited by mRNA-1273 vaccination bind more broadly to the receptor binding domain than do those from SARS-CoV-2 infection
}

\author{
Allison J. Greaney ${ }^{1,2}$, Andrea N. Loes ${ }^{1,3}$, Lauren E. Gentles ${ }^{1,4}$, Katharine H.D. Crawford ${ }^{1,2}$, Tyler N. Starr ${ }^{1,3}$, \\ Keara D. Malone ${ }^{1}$, Helen Y. Chu ${ }^{5}$, Jesse D. Bloom ${ }^{1,3} \#$ \\ ${ }^{1}$ Basic Sciences Division and Computational Biology Program, Fred Hutchinson Cancer Research Center; Seattle, WA 98109, USA. ${ }^{2}$ Department of Genome Sciences \& \\ Medical Scientist Training Program, University of Washington; Seattle, WA 98195, USA. ${ }^{3}$ Howard Hughes Medical Institute; Chevy Chase, MD 20815 , USA. ${ }^{4}$ Department of \\ Microbiology, University of Washington; Seattle, WA 98195, USA. ${ }^{5}$ Division of Allergy and Infectious Diseases, University of Washington; Seattle, WA 98195, USA. \\ \#Lead Contact jbloom@fredhutch.org
}

The emergence of severe acute respiratory syndrome coronavirus 2 (SARS-CoV-2) variants with mutations in key antibody epitopes has raised concerns that antigenic evolution could erode adaptive immunity elicited by prior infection or vaccination. The susceptibility of immunity to viral evolution is shaped in part by the breadth of epitopes targeted by antibodies elicited by vaccination or natural infection. To investigate how human antibody responses to vaccines are influenced by viral mutations, we used deep mutational scanning to compare the specificity of polyclonal antibodies elicited by either two doses of the mRNA-1273 COVID-19 vaccine or natural infection with SARS-CoV-2. The neutralizing activity of vaccine-elicited antibodies was more targeted to the receptor-binding domain (RBD) of the SARS-CoV-2 spike protein compared to antibodies elicited by natural infection. However, within the RBD, binding of vaccine-elicited antibodies was more broadly distributed across epitopes compared to infection-elicited antibodies. This greater binding breadth means that single RBD mutations have less impact on neutralization by vaccine sera compared to convalescent sera. Therefore, antibody immunity acquired by natural infection or different modes of vaccination may have a differing susceptibility to erosion by SARS-CoV-2 evolution.

\section{INTRODUCTION}

Mitigation of the coronavirus disease 2019 (COVID-19) pandemic will depend on population immunity acquired via infection with or vaccination against severe acute respiratory syndrome coronavirus 2 (SARS-CoV-2). Unfortunately, humans are repeatedly re-infected with the endemic "commoncold" coronaviruses (1), at least in part because these viruses evolve to escape neutralizing antibody immunity elicited by prior infection (2). SARS-CoV-2 is already undergoing similar antigenic evolution, with the recent emergence of new viral lineages with reduced neutralization by antibodies elicited by infection and vaccination (3-8). Preliminary results suggest that immunity still provides substantial protection against infection and severe disease $(9,10)$ caused by these new viral lineages; however, if SARS-CoV-2 is similar to other human coronaviruses, then, at minimum, the protection against reinfection will eventually be eroded by viral evolution.

However, unlike for other human coronaviruses, a large fraction of the population is acquiring SARS-CoV-2 immunity from vaccination rather than infection. The first two vaccines approved for emergency use in the United States were
Moderna's mRNA-1273 and Pfizer/BioNTech's BNT162b2. Both mRNA vaccines encode the full SARS-CoV-2 spike ectodomain with a transmembrane anchor and stabilizing S-2P mutations (11). It is possible that these vaccines could elicit antibodies with distinct specificities compared to natural infection due to variation in the spike (such as the S-2P mutations) or divergent immune responses to a two-dose mRNA vaccine versus infection. If the specificities differ, this could influence the impact of viral evolution on SARS-CoV-2 immunity.

To address this question, we used a combination of serological assays and deep mutational scanning to map the specificity of the human polyclonal antibody response after two doses of the mRNA-1273 vaccine. The vaccine elicited neutralizing activity that is even more targeted to the spike receptorbinding domain (RBD) than infection-elicited immunity. However, within the RBD, binding by vaccine-elicited antibodies was often less affected by single mutations. As a result, common RBD mutations sometimes eliminated less of the neutralizing activity of mRNA-1273 vaccine sera than convalescent sera, and vaccine sera retained substantial RBD- 
directed neutralization even in the presence of mutations to three major RBD neutralizing epitopes.

\section{RESULTS}

The neutralizing activity of $\mathrm{mRNA-1273}$ vaccine-elicited antibodies is more RBD-targeted than that of infectionelicited antibodies.

We studied sera from adults (ages 18-55 years) who received two doses of the Moderna mRNA-1273 vaccine in phase 1 clinical trials (12). The majority of our study focused on 14 individuals who received the $250 \mu \mathrm{g}$ dose, although we validated key conclusions with a smaller subset of eight trial participants who received the $100 \mu \mathrm{g}$ dose. The sera were collected at 36 and 119 days after the first vaccine dose, corresponding to 7 and 90 days after the second dose. It was previously shown that these individuals had high amounts of binding and neutralizing antibodies against SARS-CoV-2, with neutralizing antibody titers within the upper quartile of sera from SARS-CoV-2 convalescent individuals (12). Throughout, we compared vaccine sera to convalescent plasma or serum samples from two independent cohorts (13, 14). The convalescent plasma samples were characterized in earlier studies (13-16), and grouped into an early time point of 15-60 days post-symptom onset and a late time point of 100-150 days post-symptom onset.

The majority of the neutralizing activity of convalescent sera and plasma is due to RBD-binding antibodies $(15,17,18)$. To determine if neutralization by vaccine sera is similarly RBD-targeted, we depleted RBD-binding antibodies from the day 36 and 119 sera isolated from 14 individuals who received the $250 \mu \mathrm{g}$ dose of the mRNA-1273 vaccine. We then measured serum IgG binding to the RBD and full spike ectodomain before and after depletion. As expected, depletion removed all RBD-binding antibodies (Fig. 1A, fig. S1A and B). However, depleting RBD-binding antibodies only moderately decreased spike-binding activity in either vaccine sera or convalescent plasma (Fig. 1B, fig. S1B), consistent with studies showing that a minority of spike-binding vaccine-elicited B cells target the $\operatorname{RBD}(5,19)$.

To determine the contribution of RBD-binding antibodies to neutralization, we measured the neutralizing activity of vaccine sera before and after depleting RBD-binding antibodies using spike-pseudotyped lentiviral particles. For samples isolated from 13 of 14 vaccinated individuals, greater than $90 \%$ of the neutralizing activity at both time points was dependent upon RBD-binding antibodies (Fig. 1C and D, data file S1). For 17 of 28 vaccine sera, depletion of RBD-binding antibodies reduced the neutralization titer (reciprocal $\mathrm{IC}_{50}$ ) from $>1000$ to $<25$ (Fig. 1C and D, fig. S1C and D). The percent neutralizing activity due to RBD-binding antibodies was higher for vaccine sera than for convalescent plasma samples collected between day 15 and $60\left(p=1.0 \times 10^{-6}\right.$, Fig. $1 C$ and
D) (15). These assays were performed in 293T cells overexpressing human angiotensin-converting enzyme 2 (ACE2), which may underestimate contributions of non-RBD-binding antibodies to viral neutralization $(6,20,21)$. Nonetheless, because the same assay was used for vaccine and convalescent samples, we conclude that the neutralizing activity of the antibody response elicited by the mRNA-1273 vaccine is more targeted to the RBD than for infection-elicited antibodies.

Complete mapping of RBD mutations that reduce binding by vaccine-elicited sera at 119 days post-vaccination reveals broad binding specificity across multiple RBD epitopes.

We used deep mutational scanning $(15,22)$ to map all mutations to yeast-displayed RBD that reduced vaccine serum antibody binding. Our experiments utilized duplicate libraries containing 3,804 of the 3,819 possible single amino-acid mutations to the RBD of the Wuhan-Hu-1 strain of SARSCoV-2, 2,034 of which are tolerated for proper protein folding and at least modest ACE2 binding (23). We incubated the yeast-displayed libraries with each serum, and used fluorescence-activated cell sorting (FACS) to enrich for the $3-5 \%$ of cells expressing RBD mutants with the lowest amount of serum binding (fig. S2, S3, table S1). The degree to which mutations reduce serum binding varies across samples, so the FACS gates were set separately for each sample. We used deep sequencing to quantify the "escape fraction" for each of the 2,034 tolerated RBD mutations against each serum by determining the frequency of each mutant in the serum-escape bin versus the original unsorted population. These escape fractions range from 0 (no cells with the mutation in the serum-escape bin) to 1 (all cells with the mutation in the serumescape bin) (data file S2). Correlations between escape fractions measured for independent biological replicate libraries are shown in Fig. S4. We represent the escape maps as logo plots, where the height of each letter is proportional to its escape fraction (Fig. 2, fig. S5 and S6).

The escape maps for sera collected at day 119 from individuals who received the $250 \mu \mathrm{g}$ vaccine dose fell into four qualitative categories (24) (Fig. $2 A$ and B). For 5 of 14 individuals, escape from antibody binding was focused on RBD sites 456 and 484 (Fig. 2B and C, fig. S5). These two sites are on the receptor-binding ridge in the neutralizing "class 1 " and "class 2" RBD epitopes, respectively (24) (Fig. 2A). Two more individuals also had escape maps that were focused on sites 456 and 484, but with a very low overall magnitude of escape (Fig. 2B and C, fig. S5). For 2 of 14 individuals, serum binding was most affected by mutations in the "class 4" epitope located in the core RBD, including sites 383 to 386 (Fig. 2, fig. S5). Antibodies targeting the class 4 epitope are often non-neutralizing or less potently neutralizing than antibodies targeting the receptor-binding motif $(17,18,25,26)$. The escape maps for the remaining 5 individuals were "flat," 
meaning that no single mutation had a large effect on serum binding, suggestive of broad binding to multiple RBD epitopes (Fig. 2B and C, fig. S5).

To determine if the vaccine dose affected the RBD binding specificity of the polyclonal antibody response, we mapped binding escape from the day 119 sera from 8 individuals vaccinated with $100 \mu \mathrm{g}$ rather than $250 \mathrm{ug}$ doses. The escape maps of the $100 \mu \mathrm{g}$ cohort resembled those of the $250 \mu \mathrm{g}$ cohort and fell into the 456/484-targeting, core-targeting, or "flat" categories (fig. S6). Although the sample sizes are small, and a higher fraction of the $100 \mu \mathrm{g}$ dose escape maps were "flat" than for the $250 \mu \mathrm{g}$ cohort (4/8 versus $5 / 14$, respectively), this suggests 100 and 250 ug doses elicit antibody responses similar in the breadth of their RBD binding specificity.

Binding escape maps become more targeted to specific sites in the RBD from 36 days to 119 days post-vaccination.

To examine longitudinal changes in binding specificity of vaccine-elicited serum antibodies to the RBD, we also determined binding-escape maps for sera collected at day 36 postvaccination from five individuals who received the $250 \mu \mathrm{g}$ dose (Fig. 3). All of these day-36 sera had relatively "flat" escape maps, meaning that no single mutation had a large effect on serum binding (Fig. 3A). However, by day 119, the escape maps for most individuals were more focused on specific sites in the RBD (Fig. 3B). Specifically, for four of five individuals, the escape maps became focused on RBD sites 456 and 484 (Fig. 3B). For one of these individuals, the focusing on sites 456 and 484 was accompanied by increased focusing on the class 4 epitope, including sites 383-386. Only one individual, M12, had a day-119 escape map as flat as the day-36 escape map. These results suggest that, as the vaccineinduced RBD-binding antibody response matures over time, it becomes more focused on specific sites in the RBD.

RBD binding by vaccine-elicited serum samples is broader than for convalescent plasma samples.

To elucidate differences in the specificity of the RBDbinding antibody response elicited by vaccination versus infection, we compared the vaccine-sera escape maps to ones that we previously determined for convalescent plasma samples $(15,16)$. At both 15-60 day and 100-150 day ranges, the convalescent escape maps were more focused on specific RBD sites than the vaccine escape maps (Fig. 4A). The difference was especially striking at the early time point, where the day 36 vaccine samples all had flat escape maps, whereas the convalescent samples often had escape maps indicating that antibody binding was strongly affected by mutations at specific RBD sites such as 456 and 484 (Fig. 4A). The difference between the vaccine and convalescent samples was less striking at the later time point, but the convalescent maps were still more focused than the vaccine maps, as demonstrated by the lower magnitude of the escape fractions. There were also differences in the RBD sites where mutations affected binding for the vaccine versus convalescent samples. Although most samples of both types were affected by mutations at sites 456 and 484, the convalescent samples tended to also be affected by mutations to the 443-450 loop in the class 3 epitope, whereas mutations in the class 4 epitope spanning sites 383386 sometimes had a more pronounced effect on the vaccine samples (Fig. 2 and 4A, fig. S5).

To visualize relationships between vaccine- and infectionelicited antibody responses, we used multidimensional scaling to create a two-dimensional projection of the escape maps for the vaccine serum samples, convalescent plasma samples $(15,16)$, and previously characterized monoclonal antibodies $(16,22,27-29)$ (Fig. 4B, an interactive version where you can mouse over points for details is at https://jbloomlab.github.io/SARS-CoV-2-RBD_MAP_Moderna/mds.html).

In this projection, monoclonal antibodies, sera samples, or plasma samples with similar binding-escape mutations are located close together, whereas those affected by distinct mutations are far apart. As previously reported (16), convalescent plasma samples clustered closest to class 2 antibodies (Fig. 4B), which are generally most affected by mutations to site 484 . In contrast, the vaccine sera were more centrally located in the middle of the antibodies of all four classes, reflecting their flatter binding-escape maps that were less dominated by mutations that escape any single antibody class (Fig. 4B).

To examine sites of binding-escape mutations in the context of the RBD's structure, we projected the total escape at each site averaged across all vaccine or convalescent samples at each time point onto the surface of the RBD (Fig. 4C). The sites where mutations affected binding of vaccine sera were broadly distributed across the RBD surface (Fig. 4C), whereas convalescent plasma samples were most affected by mutations at just a few key regions (sites 456 and 484, and to a lesser degree the 443-450 loop) (Fig. 4C). However, as noted above, binding escape from the vaccine sera was somewhat more focused at day 119 relative to day 36 , including at sites 456, 484, and 383-386.

\section{Single RBD mutations have less impact on vaccine-elic- ited antibody neutralizing activity than infection-elic- ited antibody neutralizing activity.}

We tested key RBD mutations in spike-pseudotyped lentiviral neutralization assays against a subset of vaccine and convalescent sera. We used the binding-escape maps to choose six representative samples each from the day 100-150 vaccine and convalescent sera for which $>90 \%$ of the neutralizing activity was due to RBD-binding antibodies (Fig. 1, fig. S1) (15). The escape maps for the vaccine and convalescent samples chosen for these assays are summarized in Fig. 5A and detailed in Fig. 2 and Fig. S7. 
We performed neutralization assays on mutants in each of the four major RBD epitopes (class 1, K417N and F456A; class 2, E484P and E484K; class 3, G446V and L452R; class 4, P384R). Among these mutations, K417N, L452R, and E484K are present in emerging viral lineages, including B.1.351, P.1, B.1.427/429, B.1.526, and B.1.617 (30-35) that have been shown to have reduced neutralization $(3,5-8,36,37)$. We also tested a triple mutant, K417N-G446V-E484K, with mutations in the class 1, 2, and 3 epitopes. For many convalescent sera, single RBD mutations reduced neutralization by approximately the same amount as removing all RBD-binding antibodies (Fig. 5B, fig. S8 and S9, data file S3). However, no single RBD mutation we tested had a comparably large effect on vaccine sera (Fig. 5B). This result is consistent with the binding-escape maps, which generally indicate that vaccine sera have a broader RBD-binding specificity than convalescent sera.

The mutations that most impacted neutralization also differed between vaccine and convalescent sera (Fig. 5B). For convalescent sera, the largest reduction in neutralization was consistently caused by mutations to site E484 in the class 2 epitope $(16,22)$, including the $\mathrm{E} 484 \mathrm{~K}$ mutation present in multiple emerging viral lineages $(30,33,35)$. In contrast, E484K generally caused a more moderate decrease in neutralization for vaccine sera. For some vaccine sera, another mutation at site E484 (E484P) caused a larger loss of neutralization, but E484P has not been found in any sequenced isolates of SARS-CoV-2 and has been shown to reduce both ACE2 binding affinity (23) and viral entry titers (fig. S8D). The F456A mutation to the class 1 epitope often reduced neutralization by vaccine sera, although it had little effect on convalescent sera; this mutation is also not observed in natural sequences and reduces viral entry titers (fig. S8D). Mutations to the class 3 epitope (G446V, L452R) modestly reduced neutralization by some vaccine and convalescent sera (Fig. 5B). However, P384R in the less-neutralizing core RBD class 4 epitope $(17,18,25,26)$ and $\mathrm{K} 417 \mathrm{~N}$ in the class 1 epitope had little effect on neutralization by any sera, consistent with previous reports $(5-7,38)$. Importantly, although single mutations sometimes caused large decreases in neutralization by convalescent sera, in no case did they reduce neutralization by vaccine sera $>10$-fold or to a titer $<100$ (Fig. 5B, fig. S8).

The fact that single mutations ablated the anti-RBD neutralizing activity of some convalescent sera, but only modestly eroded the activity of vaccine sera, suggests that the vaccine elicits neutralizing antibodies with a greater number of RBD specificities. To test this idea, we performed neutralization assays with a triple mutant (K417N-G446V-E484K) containing a mutation in each of the class 1,2 , and 3 epitopes. For convalescent sera, the $\mathrm{E} 484 \mathrm{~K}$ mutation alone often caused a decrease in neutralization comparable to the triple mutant (Fig. 5C and D, fig. S8), consistent with the convalescent escape maps showing a strong focus on site E484. In contrast, for vaccine sera, the triple mutant always reduced neutralization more than any of its constituent single mutations (Fig. 5C and D, fig. S8). Moreover, the triple mutant decreased neutralization to the same extent as removing all RBDbinding antibodies for only one out of the six vaccine sera samples tested (Fig. 5B), indicating that the vaccine usually induces some neutralizing antibodies not escaped by mutations to sites K417, G446, and E484. These results are consistent with the escape maps indicating that the vaccine sera often have a broader RBD-binding specificity. Of note, infection also elicited very broad anti-RBD neutralizing activity in some cases; for instance, serum from the convalescent individual with the broadest escape map (participant G, day 94) was substantially more affected by the triple mutant than any of its constituent single mutants (Fig. 5B, fig. S7 and S8).

\section{DISCUSSION}

In this study, we have shown differences in the specificity of polyclonal serum antibodies acquired by infection versus vaccination with mRNA-1273. The neutralizing activity of vaccine sera is more targeted to the RBD than for convalescent sera, with the majority of vaccine sera losing all detectable neutralization at a 1:25 cutoff after depletion of RBD-directed antibodies. This fact is surprising, since the mRNA-1273 vaccine encodes the full spike ectodomain (11), and one conjectured benefit of full-spike versus RBD-only vaccines was elicitation of neutralizing antibodies targeting non-RBD subdomains.

At first glance, the RBD targeting of the vaccine sera neutralization might seem likely to increase susceptibility to viral mutations, but the rest of our results suggest that this may not be the case. Our comprehensive maps of how RBD mutations reduce serum antibody binding show that vaccine-elicited antibodies are usually less affected by any single RBD mutation than infection-elicited antibodies. Whereas infection-elicited RBD antibodies are often strongly focused on an epitope including site E484, vaccine-elicited antibodies bind more broadly across the RBD, including to the more conserved "core" regions. This broader binding makes neutralization by vaccine sera more resistant to mutations within the RBD. For instance, RBD-directed neutralization by convalescent sera was greatly reduced or even eliminated by a combination of key mutations at the three major epitopes in the RBD's receptor-binding motif, but all vaccine sera that we tested retained substantial neutralization against this triple mutant. This result implies that either vaccination induces an antibody response more broadly distributed across the RBD surface, or that the individual antibodies elicited by vaccination are more robust to these mutations $(39,40)$. Our results are consistent with a recent study by Amanat et al., which reported that several single RBD mutations reduce binding of serum from individuals vaccinated with the Pfizer mRNA 
vaccine less than for serum from previously infected individuals (19).

We found that the specificity of the mRNA-1273 vaccineinduced RBD-binding antibody response often narrows over time. In contrast, the infection-elicited RBD-binding antibody response often broadens over time $(15,39)$. However, because the early vaccine-induced RBD-binding antibody response is so broad compared to that induced by infection, even with these contrasting dynamics, the vaccine response remains broader than the convalescent response at late time points of 3-4 months. Additionally, the overall antibody response is more homogeneous for vaccinated than convalescent individuals. For instance, the RBD binding titers, neutralizing titers, amount of neutralization derived from RBD-binding antibodies, and effects of mutations on neutralization were more uniform for the vaccinated cohort than the convalescent cohort.

Our results do not explain why there are differences between the vaccine- and infection-elicited antibody responses, but we note two possibilities. First, the vaccine encodes a stabilized S-2P spike, which could present some epitopes in slightly different conformations and lead to less S1 shedding. Second, the vaccine is delivered in a two-dose schedule by an mRNA-lipid nanoparticle, which may lead to different kinetics of antigen presentation than viral infection $(41,42)$. Indeed, another recent study suggests that mRNA vaccination elicits a different distribution of isotypes and fewer antibodies that cross-react to common-cold coronaviruses as compared to infection (43).

There are several limitations to our study. The vaccinated individuals in our study were relatively young (18-55 years) and healthy, whereas the convalescent individuals were older (23-76 years, median 56) with a range of comorbidities (13). Additionally, we did not examine effects of mutations or deletions to the N-terminal domain of the spike protein, which can also affect neutralization by vaccine sera (7). Our experiments assayed binding of antibodies to isolated RBD expressed by yeast, and so cannot capture mutational effects on trimer conformation or antibodies with quaternary epitopes (24). Finally, the N-linked glycans on yeast-expressed proteins are more mannose-rich than those on mammalian-expressed proteins (44).

Despite these limitations, our results in conjunction with other recent studies (19) suggest that mRNA vaccines and infection elicit somewhat distinct anti-spike antibody responses. Therefore, it is important to differentiate antibody immunity acquired by different means when assessing the impact of viral evolution. Considerable effort is being expended to identify emerging antigenic variants of SARS-CoV2 and determine which ones might evade immunity $(3,7,8$, 35 ). Our findings suggest that the results could vary depending on the source of immunity. Furthermore, carefully characterizing and comparing the specificity of antibody immunity elicited by additional vaccine modalities could provide a basis for determining whether some vaccine responses will be more resistant to viral evolution.

\section{MATERIALS AND METHODS}

\section{Study design}

De-identified post-vaccination sera were obtained as secondary research samples from the National Institutes of Allergy and Infectious Diseases-sponsored mRNA-1273 phase 1 clinical trial (NCT04283461) (12). We obtained samples from 14 individuals who received two $250 \mu \mathrm{g}$ doses of the mRNA1273 vaccine, and 8 individuals who received two $100 \mu \mathrm{g}$ doses. All individuals were between ages 18 and 55 years old. The study size was determined by the number of samples that were available from the phase 1 clinical trial, and not based on any power calculations. Experiments described in this manuscript were not performed blinded. The samples were collected under the human subject approvals described in (12). Due to the de-identified nature of the samples, the work described in this paper was deemed non-human subjects research by the Fred Hutchinson Cancer Research Center Institutional Review Board.

Previously reported results from samples from two cohorts of SARS-CoV-2 convalescent individuals are reanalyzed here $(15,16)$. One cohort of convalescent plasma samples were previously described $(13,15)$ and collected as part of a prospective longitudinal cohort study of individuals with SARSCoV-2 infection in Seattle, WA between February and July 2020. The plasma samples from 17 individuals were examined here $(8 / 17$ female; age range $23-76$ years, mean 51.6 years, median 56 years). All data from this cohort, including the neutralization and RBD- and spike-binding activity of plasma samples pre- and post-depletion of RBD-binding antibodies in Fig. 1 and RBD-binding escape maps in Fig. 4, fig. S6B, and fig. S7, were previously reported (15) with the exception of neutralization assays in Fig. 5, fig. S8, and fig. S9, which were performed in this study. This work was approved by the University of Washington Institutional Review Board.

All data from the second cohort of plasma samples $(n=5)$, including the aggregated escape maps in Fig. 4, were previously reported (16) and are reanalyzed here. The plasma samples were originally collected 21-35 days post-symptom onset as part of a prospective longitudinal cohort study of SARSCoV-2 convalescent individuals in New York, NY, under the human subject approvals described in (14).

\section{RBD deep mutational scanning library}

The yeast-display RBD mutant libraries were previously described $(22,23)$. Briefly, duplicate mutant libraries were constructed in the spike receptor binding domain (RBD) from SARS-CoV-2 (isolate Wuhan-Hu-1, GenBank accession number MN908947, residues N331-T531) and contain 3,804 
of the 3,819 possible amino-acid mutations, with $>95 \%$ present as single mutants. Each RBD variant was linked to a unique 16-nucleotide barcode sequence to facilitate downstream sequencing. As previously described, libraries were sorted for RBD expression and ACE2 binding to eliminate RBD variants that are completely misfolded or non-functional, such as those lacking modest ACE2 binding affinity (22).

\section{FACS sorting of yeast libraries to select mutants with re- duced binding by polyclonal post-vaccination sera}

Serum mapping experiments were performed in biological duplicate using the independent mutant RBD libraries, similarly to as previously described for monoclonal antibodies (22) and exactly as previously described for polyclonal plasma samples (15). Briefly, mutant yeast libraries induced to express RBD were washed and incubated with serum at a range of dilutions for 1 hour at room temperature with gentle agitation. For each serum, we chose a sub-saturating dilution such that the amount of fluorescent signal due to serum antibody binding to RBD was approximately equal across samples. The exact dilution used for each serum is given in table S1. After the serum incubations, the libraries were secondarily labeled for 1 hour with 1:100 fluorescein isothiocyanateconjugated anti-MYC antibody (Immunology Consultants Lab, CYMC-45F) to label for RBD expression and 1:200 Alexa Fluor-647-conjugated goat anti-human-IgA+IgG+IgM (Jackson ImmunoResearch 109-605-064) to label for bound serum antibodies. A flow cytometric selection gate was drawn to capture $3-6 \%$ of the RBD mutants with the lowest amount of serum binding for their degree of RBD expression (fig. S2 and S3). We also measured what fraction of cells expressing unmutated RBD fell into this gate when stained with $1 \mathrm{x}$ and $0.1 x$ the concentration of serum. For each sample, approximately 10 million $\mathrm{RBD}^{+}$cells (range $7.3 \mathrm{e} 6$ to $1.4 \mathrm{e} 7$ cells) were processed on the BD FACSAria II cell sorter, with between 3 e5 and 6 e5 plasma-escaped cells collected per sample (table S1). Antibody-escaped cells were grown overnight in synthetic defined medium with casamino acids $(6.7 \mathrm{~g} / \mathrm{L}$ Yeast Nitrogen Base, $5.0 \mathrm{~g} / \mathrm{L}$ Casamino acids, $1.065 \mathrm{~g} / \mathrm{L}$ MES acid, and $2 \% \mathrm{w} / \mathrm{v}$ dextrose) to expand cells prior to plasmid extraction.

\section{DNA extraction and Ilumina sequencing}

Plasmid samples were prepared from 30 optical density (OD) units (1.6e 8 colony forming units (cfus)) of pre-selection yeast populations and approximately 5 OD units ( $\sim 3.2 \mathrm{e} 7 \mathrm{cfus})$ of overnight cultures of serum-escaped cells (Zymoprep Yeast Plasmid Miniprep II) as previously described (22). The 16-nucleotide barcode sequences identifying each RBD variant were amplified by polymerase chain reaction (PCR) and prepared for Illumina sequencing as described in (23). Barcodes were sequenced on an Illumina HiSeq 2500 with 50 bp singleend reads. To minimize noise from inadequate sequencing coverage, we ensured that each antibody-escape sample had at least $2.5 \mathrm{x}$ as many post-filtering sequencing counts as FACS-selected cells, and reference populations had at least 2.5e7 post-filtering sequencing counts.

\section{Analysis of deep sequencing data to compute each muta- tion's escape fraction}

Escape fractions were computed as described in (22), with minor modifications as noted below. We used the dms_variants package (https://jbloomlab.github.io/dms_variants/, version 0.8.5) to process Illumina sequences into counts of each barcoded RBD variant in each pre-sort and antibodyescape population using the barcode/RBD look-up table from (23). For each serum selection, we computed the "escape fraction" for each barcoded variant using the deep sequencing counts for each variant in the original and serum-escape populations and the total fraction of the library that escaped antibody binding via the formula provided in (22). These escape fractions represent the estimated fraction of cells expressing that specific variant that falls in the escape bin, such that a value of 0 means the variant is always bound by serum and a value of 1 means that it always escapes serum binding. We then applied a computational filter to remove variants with low sequencing counts or highly deleterious mutations that might cause antibody escape simply by leading to poor expression of properly folded RBD on the yeast cell surface (22, 23). Specifically, we removed variants that had (or contained mutations with) ACE2 binding scores $<-2.35$ or expression scores $<-1$, using the variant- and mutation-level deep mutational scanning scores from (23). Note that these filtering criteria are slightly more stringent than those used in (22) but are identical to those used in $(15,16,27)$.

We next deconvolved variant-level escape scores into escape fraction estimates for single mutations using global epistasis models (45) implemented in the dms_variants package, as detailed at https://jbloomlab.github.io/dms_variants/dms_variants.globalepistasis.html and described in (22). The reported scores throughout the paper are the average across the libraries; these scores are also in data file S2. Correlations in final single-mutant escape scores are shown in fig. S4.

For plotting and analyses that required identifying RBD sites of "strong escape", we considered a site to mediate strong escape if the total escape (sum of mutation-level escape fractions) for that site exceeded the median across sites by $>5$-fold, and was at least $5 \%$ of the maximum for any site. Full documentation of the computational analysis is at https://github.com/jbloomlab/SARS-CoV-2-

RBD_MAP_Moderna and archived in the Zenodo code repository under doi 10.5281 /zenodo.4741330.

\section{Generation of pseudotyped lentiviral particles}

HEK-293T (American Type Culture Collection, CRL-3216) cells were used to generate SARS-CoV-2 spike-pseudotyped lentiviral particles and 293T-ACE2 cells (Biodefense and 
Emerging Infectious Research Resources Repository (BEI Resources), NR-52511) were used to titer the SARS-CoV-2 spikepseudotyped lentiviral particles and to perform neutralization assays (see below). We used spike-pseudotyped lentiviral particles that were generated essentially as described in (46), using a codon-optimized SARS-CoV-2 spike from Wuhan-Hu1 strain that contains a 21-amino-acid deletion at the end of the cytoplasmic tail (13) and the D614G mutation that is now predominant in human SARS-CoV-2 (47). The plasmid encoding this spike, HDM_Spikedelta21_D614G, is available from Addgene (\#158762) and BEI Resources (NR-53765), and the full sequence is at (https://www.addgene.org/158762). Point mutations were introduced into the RBD of this plasmid via site-directed mutagenesis. Therefore, all mutations tested in this paper are in the G614 background, and are compared to a "wild-type" spike with G614.

To generate these spike-pseudotyped lentiviral particles (46), 6e5 HEK-293T (ATCC CRL-3216) cells per well were seeded in 6-well plates in $2 \mathrm{~mL}$ D10 growth media (Dulbecco's Modified Eagle Medium with 10\% heat-inactivated fetal bovine serum, $2 \mathrm{mM}$ l-glutamine, $100 \mathrm{U} / \mathrm{mL}$ penicillin, and 100 $\mu \mathrm{g} / \mathrm{mL}$ streptomycin). 24 hours later, cells were transfected using BioT transfection reagent (Bioland Scientific) with a Luciferase_IRES_ZsGreen backbone, Gag/Pol lentiviral helper plasmid (BEI Resources NR-52517), and wild-type or mutant SARS-CoV-2 spike plasmids. Media was changed to fresh D10 at 24 hours post-transfection. At $\sim 60$ hours posttransfection, viral supernatants were collected, filtered through a $0.45 \mu \mathrm{m}$ surfactant-free cellulose acetate low protein-binding filter, and stored at $-80^{\circ} \mathrm{C}$.

\section{Titering of pseudotyped lentiviral particles}

Titers of spike-pseudotyped lentiviral particles were determined as described in (46) with the following modifications. $100 \mu \mathrm{L}$ of diluted spike-pseudotyped lentiviral particles was added to 1.25e4 293T-ACE2 cells (BEI Resources NR52511 ), grown overnight in $50 \mu \mathrm{L}$ of D10 growth media in a 96-well black-walled poly-L-lysine coated plate (Greiner BioOne, 655936). Relative luciferase units (RLU) were measured 65 hours post-infection (Promega Bright-Glo, E2620) in the infection plates with a black back-sticker (Thermo Fisher Scientific, NC9425162) added to minimize background. Titers were first estimated from the average of 8 two-fold serial dilutions of virus starting at $25 \mu \mathrm{L}$ virus in a total volume of 150 $\mu \mathrm{L}$, performed in duplicate, and normalized to a wild-type D614G variant harvested on the same day. Quantitative titering was then performed at a single virus dilution, targeting 200,000 RLU per well. Values in fig. S8D are an average RLUs per $\mu \mathrm{L}$ measured across 16 technical replicates at a single dilution.

\section{Neutralization assays}

293T-ACE2 cells (BEI Resources NR-52511) were seeded at
$1.25 \mathrm{e} 4$ cells per well in $50 \mu \mathrm{L}$ D10 in poly-L-lysine coated, black-walled, 96-well plates (Greiner 655930). 24 hours later, pseudotyped lentivirus supernatants were diluted to $\sim 200,000$ RLU per well (determined by titering as described above and incubated with a range of dilutions of serum for 1 hour at $37^{\circ} \mathrm{C} .100 \mu \mathrm{L}$ of the virus-antibody mixture was then added to cells. At about 50 or 70 hours post-infection, luciferase activity was measured using the Bright-Glo Luciferase Assay System (Promega, E2610). Fraction infectivity of each serum antibody-containing well was calculated relative to a "no-serum" well inoculated with the same initial viral supernatant (containing wild-type or mutant $\mathrm{RBD}$ ) in the same row of the plate. We used the neutcurve package (https://jbloomlab.github.io/neutcurve version 0.5.2) to calculate the inhibitory concentration $50 \%\left(\mathrm{IC}_{50}\right)$ and the neutralization titer $50 \%\left(\mathrm{NT}_{50}\right)$, which is $1 / \mathrm{IC}_{50}$, of each serum against each virus by fitting a Hill curve with the bottom fixed at 0 and the top fixed at 1 .

\section{Depletion of RBD-binding antibodies from polyclonal} sera

Two rounds of sequential depletion of RBD-binding antibodies were performed for vaccine-elicited sera. Magnetic beads conjugated to the SARS-CoV-2 RBD (AcroBiosystems, MBS-K002) were prepared according to the manufacturer's protocol. Beads were resuspended in ultrapure water at $1 \mathrm{mg}$ beads/mL and a magnet was used to wash the beads 3 times in phosphate-buffered saline (PBS) with $0.05 \%$ bovine serum albumin (BSA). Beads were then resuspended in PBS with $0.05 \% \mathrm{BSA}$ at $1 \mathrm{mg}$ beads per $\mathrm{mL}$. Beads (manufacturer-reported binding capacity of $10-40 \mu \mathrm{g} / \mathrm{mL}$ anti-RBD antibodies) were incubated with human sera at a 3:1 ratio beads:serum (150 $\mu \mathrm{L}$ beads $+50 \mu \mathrm{L}$ serum), rotating overnight at $4^{\circ} \mathrm{C}$. A magnet (MagnaRack Magnetic Separation Rack, Thermo Fisher Scientific, CS15000) was used to separate antibodies that bind $\mathrm{RBD}$ from the supernatant, and the supernatant (the post-RBD antibody depletion sample) was removed. A mock depletion (pre-depletion sample) was performed by adding $150 \mu \mathrm{L}$ of PBS $+0.05 \%$ BSA and incubating rotating overnight at $4^{\circ} \mathrm{C}$. A second round of depletion was then performed to ensure full depletion of RBD-binding antibodies. For the neutralization assays on these sera depleted of RBD-binding antibodies, the reported serum dilution is corrected for the dilution incurred by the depletion process.

\section{Measurement of serum binding to RBD or spike by en- zyme-linked immunosorbent assay (ELISA)}

The IgG ELISAs for spike protein and RBD were conducted as previously described (48). Briefly, ELISA plates were coated with recombinant spike and RBD antigens described in (48) at $2 \mu \mathrm{g} / \mathrm{mL}$. Five 3-fold serial dilutions of sera beginning at 1:500 were performed in PBS with 0.1\% Tween with 1\% Carnation nonfat dry milk. Dilution series of the "synthetic" sera comprised of the anti-RBD antibody 
REGN10987 (49) or anti-N-terminal domain antibody 4A8 (21) and pooled pre-pandemic human serum from 2017-2018 (Gemini Biosciences; nos. 100-110, lot H86W03J; pooled from 75 donors) were performed such that the anti-spike antibody was present at a highest concentration of $0.25 \mu \mathrm{g} / \mathrm{mL}$. Both antibodies were recombinantly produced by Genscript. The rREGN10987 is that used in (27) and the variable domain heavy and light chain sequences for r4A8 were obtained from GenBank GI 1864383732 and 1864383733 (21) and produced on a human IgG1 and IgK background, respectively. Pre-pandemic serum alone, without anti-RBD antibody depletion, was used as a negative control, averaged over 2 replicates. Secondary labeling was performed with goat anti-human IgG-Fc horseradish peroxidase (HRP) (1:3000, Bethyl Labs, A80-104P). Antibody binding was detected with TMB/E HRP substrate (Millipore Sigma, ESO01) and $1 \mathrm{~N} \mathrm{HCl}$ was used to stop the reaction. $\mathrm{OD}_{450}$ was read on a Tecan infinite M1000Pro plate reader. The area under the curve (AUC) was calculated using the scikit-learn python package, version 0.23 .2 (https://scikit-learn.org/stable/) as the area under the titration curve with the serial dilutions on a log-scale.

\section{Data visualization}

The static logo plot visualizations of the escape maps in the paper figures were created using the dmslogo package (https://jbloomlab.github.io/dmslogo, version 0.6.2) and in all cases the height of each letter indicates the escape fraction for that amino-acid mutation calculated as described above. For each sample, the y-axis is scaled to be the greatest of (a) the maximum site-wise escape metric observed for that sample, (b) 20x the median site-wise escape fraction observed across all sites for that serum, or (c) an absolute value of 1.0 (to appropriately scale samples that are not "noisy" but for which no mutation has a strong effect on antibody binding). Sites K417, L452, S477, E484, and N501 have been added to logo plots due to their frequencies among circulating viruses. The code that generates these logo plot visualizations is available at https://github.com/jbloomlab/SARS-CoV-2RBD_MAP_Moderna/blob/main/results/summary/escape_p rofiles.md and archived in the Zenodo code repository (doi 10.5281/zenodo.4741330). In many of the visualizations, the RBD sites are categorized by epitope region (24) and colored accordingly. We define the class 1 epitope as residues $403+405+406+417+420+421+453+455-460+473-$

$476+486+487+489+504$, the class 2 epitope as residues $472+483-485+490-494$, the class 3 epitope to be residues $345+346+437-452+496+498-501$, and the class 4 epitope as residues $365-372+382-386$.

For the static structural visualizations in the paper figures, the RBD surface (PDB 6MOJ, (50)) was colored by the site-wise escape metric at each site, with white indicating no escape and red scaled to be the same maximum used to scale the y-axis in the logo plot escape maps, determined as described above. We created interactive structure-based visualizations of the escape maps using dms-view (51) that are available at https://jbloomlab.github.io/SARS-CoV-2RBD_MAP_Moderna/. The logo plots in these escape maps can be colored according to the deep mutational scanning measurements of how mutations affect ACE2 binding or RBD expression as described above.

For the composite line plots shown in Fig. 4, the convalescent (day 15-60) group includes two independent cohorts of individuals, one recruited in New York, NY $(n=5)(14)$, and another recruited in Seattle, WA $(n=11)(13)$. The convalescent (day 100-150) group is from the longitudinal cohort recruited in Seattle, WA ( $\mathrm{n}=11)$. The escape maps for convalescent individuals were previously reported in $(15,16)$. The mRNA-1273 (day 119) group includes individuals who were vaccinated with either the 100 or $250 \mu \mathrm{g}$ vaccine dose $(\mathrm{n}=8$ and $\mathrm{n}=14$, respectively). The y-axis maximum is scaled to 1.1 times the maximum group mean site-total escape among all groups, so outlier points exceeding this value are not shown.

\section{Statistical Analysis}

The percent of neutralizing activity of vaccine-elicited sera and convalescent plasma due to RBD-binding antibodies is plotted with the plotnine python package, version 0.7.1 (https://plotnine.readthedocs.io/en/stable/index.html), shown as a Tukey boxplot (middle line indicating median, box limits indicating interquartile range) with individual measurements overlaid as points. P-values are from a logrank test accounting for censoring, calculated with the lifelines python package, version 0.25 .10 (https://lifelines.readthedocs.io/en/latest/).

\section{SUPPLEMENTARY MATERIALS}

stm.sciencemag.org/cgi/content/full/scitranslmed.abi9915/DC1 Figs. S1 to S9

Table S1

Data file S1 to S3

\section{REFERENCES AND NOTES}

1. O. W. Schmidt, I. D. Allan, M. K. Cooney, H. M. Foy, J. P. Fox, Rises in titers of antibody to human coronaviruses OC43 and 229E in Seattle families during 1975-1979. Am. J. Epidemiol. 123, 862-868 (1986). doi:10.1093/oxfordjournals.aje.a114315 Medline

2. R. T. Eguia, K. H. D. Crawford, T. Stevens-Ayers, L. Kelnhofer-Millevolte, A. L. Greninger, J. A. Englund, M. J. Boeckh, J. D. Bloom, A human coronavirus evolves antigenically to escape antibody immunity. PLOS Pathog. 17, e1009453 (2021). doi:10.1371/journal.ppat.1009453 Medline

3. S. Cele, I. Gazy, L. Jackson, S.-H. Hwa, H. Tegally, G. Lustig, J. Giandhari, S. Pillay, E. Wilkinson, Y. Naidoo, F. Karim, Y. Ganga, K. Khan, M. Bernstein, A. B. Balazs, B. I. Gosnell, W. Hanekom, M. S. Moosa, R. J. Lessells, T. de Oliveira, A. Sigal; Network for Genomic Surveillance in South Africa; COMMIT-KZN Team, Escape of SARSCoV-2 501Y.V2 from neutralization by convalescent plasma. Nature 593, 142-146 (2021). doi:10.1038/s41586-021-03471-w Medline

4. W. F. Garcia-Beltran, E. C. Lam, K. St Denis, A. D. Nitido, Z. H. Garcia, B. M. Hauser, J. Feldman, M. N. Pavlovic, D. J. Gregory, M. C. Poznansky, A. Sigal, A. G. Schmidt, A. J. lafrate, V. Naranbhai, A. B. Balazs, Multiple SARS-CoV-2 variants escape neutralization by vaccine-induced humoral immunity. Cell 184, 2372-2383.e9 (2021). doi:10.1016/j.cell.2021.03.013 Medline

5. Z. Wang, F. Schmidt, Y. Weisblum, F. Muecksch, C. O. Barnes, S. Finkin, D. Schaefer- 
Babajew, M. Cipolla, C. Gaebler, J. A. Lieberman, T. Y. Oliveira, Z. Yang, M. E. Abernathy, K. E. Huey-Tubman, A. Hurley, M. Turroja, K. A. West, K. Gordon, K. G. Millard, V. Ramos, J. Da Silva, J. Xu, R. A. Colbert, R. Patel, J. Dizon, C. UnsonO'Brien, I. Shimeliovich, A. Gazumyan, M. Caskey, P. J. Bjorkman, R. Casellas, T. Hatziioannou, P. D. Bieniasz, M. C. Nussenzweig, mRNA vaccine-elicited antibodies to SARS-CoV-2 and circulating variants. Nature 592, 616-622 (2021). doi:10.1038/s41586-021-03324-6 Medline

6. R. E. Chen, X. Zhang, J. B. Case, E. S. Winkler, Y. Liu, L. A. VanBlargan, J. Liu, J. M. Errico, X. Xie, N. Suryadevara, P. Gilchuk, S. J. Zost, S. Tahan, L. Droit, J. S. Turner, W. Kim, A. J. Schmitz, M. Thapa, D. Wang, A. C. M. Boon, R. M. Presti, J. A. O'Halloran, A. H. J. Kim, P. Deepak, D. Pinto, D. H. Fremont, J. E. Crowe Jr., D. Corti, H. W. Virgin, A. H. Ellebedy, P.-Y. Shi, M. S. Diamond, Resistance of SARS-CoV-2 variants to neutralization by monoclonal and serum-derived polyclonal antibodies. Nat. Med. 27, 717-726 (2021). doi:10.1038/s41591-021-01294-w Medline

7. P. Wang, M. S. Nair, L. Liu, S. Iketani, Y. Luo, Y. Guo, M. Wang, J. Yu, B. Zhang, P. D. Kwong, B. S. Graham, J. R. Mascola, J. Y. Chang, M. T. Yin, M. Sobieszczyk, C. A. Kyratsous, L. Shapiro, Z. Sheng, Y. Huang, D. D. Ho, Antibody resistance of SARSCoV-2 variants B.1.351 and B.1.1.7. Nature 593, 130-135 (2021). doi:10.1038/s41586-021-03398-2 Medline

8. C. K. Wibmer, F. Ayres, T. Hermanus, M. Madzivhandila, P. Kgagudi, B. Oosthuysen, B. E. Lambson, T. de Oliveira, M. Vermeulen, K. van der Berg, T. Rossouw, M. Boswell, V. Ueckermann, S. Meiring, A. von Gottberg, C. Cohen, L. Morris, J. N. Bhiman, P. L. Moore, SARS-CoV-2 501Y.V2 escapes neutralization by South African COVID-19 donor plasma. Nat. Med. 27, 622-625 (2021). doi:10.1038/s41591-021-01285-x Medline

9. Novavax COVID-19 Vaccine Demonstrates $89.3 \%$ Efficacy in UK Phase 3 Trial, (available at https://ir.novavax.com/news-releases/news-releasedetails/novavax-covid-19-vaccine-demonstrates-893-efficacy-uk-phase-3).

10. Pfizer and BioNTech Confirm High Efficacy and No Serious Safety Concerns Through Up to Six Months Following Second Dose in Updated Topline Analysis of Landmark COVID-19 Vaccine Study, (available at https://www.pfizer.com/news/press-release/press-release-detail/pfizer-andbiontech-confirm-high-efficacy-and-no-serious).

11. K. S. Corbett, D. K. Edwards, S. R. Leist, O. M. Abiona, S. Boyoglu-Barnum, R. A. Gillespie, S. Himansu, A. Schäfer, C. T. Ziwawo, A. T. DiPiazza, K. H. Dinnon, S. M. Elbashir, C. A. Shaw, A. Woods, E. J. Fritch, D. R. Martinez, K. W. Bock, M. Minai, B. M. Nagata, G. B. Hutchinson, K. Wu, C. Henry, K. Bahl, D. Garcia-Dominguez, L. Ma, I. Renzi, W.-P. Kong, S. D. Schmidt, L. Wang, Y. Zhang, E. Phung, L. A. Chang, R. J. Loomis, N. E. Altaras, E. Narayanan, M. Metkar, V. Presnyak, C. Liu, M. K. Louder, W. Shi, K. Leung, E. S. Yang, A. West, K. L. Gully, L. J. Stevens, N. Wang, D. Wrapp, N. A. Doria-Rose, G. Stewart-Jones, H. Bennett, G. S. Alvarado, M. C. Nason, T. J. Ruckwardt, J. S. McLellan, M. R. Denison, J. D. Chappell, I. N. Moore, K. M. Morabito, J. R. Mascola, R. S. Baric, A. Carfi, B. S. Graham, SARS-CoV-2 mRNA vaccine design enabled by prototype pathogen preparedness. Nature 586 , 567-571 (2020). doi:10.1038/s41586-020-2622-0 Medline

12. L. A. Jackson, E. J. Anderson, N. G. Rouphael, P. C. Roberts, M. Makhene, R. N. Coler, M. P. McCullough, J. D. Chappell, M. R. Denison, L. J. Stevens, A. J. Pruijssers, A. McDermott, B. Flach, N. A. Doria-Rose, K. S. Corbett, K. M. Morabito, S. O'Dell, S. D. Schmidt, P. A. Swanson 2nd, M. Padilla, J. R. Mascola, K. M. Neuzil, H. Bennett, W. Sun, E. Peters, M. Makowski, J. Albert, K. Cross, W. Buchanan, R. Pikaart-Tautges, J. E. Ledgerwood, B. S. Graham, J. H. Beigel; mRNA-1273 Study Group, An mRNA Vaccine against SARS-CoV-2 - Preliminary Report. N. Engl. J. Med. 383, 1920-1931 (2020). doi:10.1056/NEJMoa2022483 Medline

13. K. H. D. Crawford, A. S. Dingens, R. Eguia, C. R. Wolf, N. Wilcox, J. K. Logue, K. Shuey, A. M. Casto, B. Fiala, S. Wrenn, D. Pettie, N. P. King, A. L. Greninger, H. Y. Chu, J. D. Bloom, Dynamics of neutralizing antibody titers in the months after SARS-CoV-2 infection. J. Infect. Dis. jiaa618 (2020). 10.1093/infdis/jiaa618 Medline

14. D. F. Robbiani, C. Gaebler, F. Muecksch, J. C. C. Lorenzi, Z. Wang, A. Cho, M. Agudelo, C. O. Barnes, A. Gazumyan, S. Finkin, T. Hägglöf, T. Y. Oliveira, C. Viant, A. Hurley, H.-H. Hoffmann, K. G. Millard, R. G. Kost, M. Cipolla, K. Gordon, F. Bianchini, S. T. Chen, V. Ramos, R. Patel, J. Dizon, I. Shimeliovich, P. Mendoza, H. Hartweger, L. Nogueira, M. Pack, J. Horowitz, F. Schmidt, Y. Weisblum, E. Michailidis, A. W. Ashbrook, E. Waltari, J. E. Pak, K. E. Huey-Tubman, N. Koranda,
P. R. Hoffman, A. P. West Jr., C. M. Rice, T. Hatziioannou, P. J. Bjorkman, P. D. Bieniasz, M. Caskey, M. C. Nussenzweig, Convergent antibody responses to SARS-CoV-2 in convalescent individuals. Nature 584, 437-442 (2020). doi:10.1038/s41586-020-2456-9 Medline

15. A. J. Greaney, A. N. Loes, K. H. D. Crawford, T. N. Starr, K. D. Malone, H. Y. Chu, J. D. Bloom, Comprehensive mapping of mutations in the SARS-CoV-2 receptorbinding domain that affect recognition by polyclonal human plasma antibodies. Cell Host Microbe 29, 463-476.e6 (2021). doi:10.1016/i.chom.2021.02.003 Medline

16. A. J. Greaney, T. N. Starr, C. O. Barnes, Y. Weisblum, F. Schmidt, M. Caskey, C. Gaebler, A. Cho, M. Agudelo, S. Finkin, Z. Wang, D. Poston, F. Muecksch, T. Hatziioannou, P. D. Bieniasz, D. F. Robbiani, M. C. Nussenzweig, P. J. Bjorkman, J. D. Bloom, Mutational escape from the polyclonal antibody response to SARS-CoV2 infection is largely shaped by a single class of antibodies. bioRxiv 2021.03.17.435863 (2021). Medline

17. L. Piccoli, Y.-J. Park, M. A. Tortorici, N. Czudnochowski, A. C. Walls, M. Beltramello, C. Silacci-Fregni, D. Pinto, L. E. Rosen, J. E. Bowen, O. J. Acton, S. Jaconi, B. Guarino, A. Minola, F. Zatta, N. Sprugasci, J. Bassi, A. Peter, A. De Marco, J. C. Nix, F. Mele, S. Jovic, B. F. Rodriguez, S. V. Gupta, F. Jin, G. Piumatti, G. Lo Presti, A. F. Pellanda, M. Biggiogero, M. Tarkowski, M. S. Pizzuto, E. Cameroni, C. HavenarDaughton, M. Smithey, D. Hong, V. Lepori, E. Albanese, A. Ceschi, E. Bernasconi, L. Elzi, P. Ferrari, C. Garzoni, A. Riva, G. Snell, F. Sallusto, K. Fink, H. W. Virgin, A. Lanzavecchia, D. Corti, D. Veesler, Mapping Neutralizing and Immunodominant Sites on the SARS-CoV-2 Spike Receptor-Binding Domain by Structure-Guided High-Resolution Serology. Cell 183, 1024-1042.e21 (2020). doi:10.1016/i.cell.2020.09.037 Medline

18. W. Dejnirattisai, D. Zhou, H. M. Ginn, H. M. E. Duyvesteyn, P. Supasa, J. B. Case, Y. Zhao, T. S. Walter, A. J. Mentzer, C. Liu, B. Wang, G. C. Paesen, J. Slon-Campos, C. López-Camacho, N. M. Kafai, A. L. Bailey, R. E. Chen, B. Ying, C. Thompson, J. Bolton, A. Fyfe, S. Gupta, T. K. Tan, J. Gilbert-Jaramillo, W. James, M. Knight, M. W. Carroll, D. Skelly, C. Dold, Y. Peng, R. Levin, T. Dong, A. J. Pollard, J. C. Knight, P. Klenerman, N. Temperton, D. R. Hall, M. A. Williams, N. G. Paterson, F. K. R. Bertram, C. A. Siebert, D. K. Clare, A. Howe, J. Radecke, Y. Song, A. R. Townsend, K. A. Huang, E. E. Fry, J. Mongkolsapaya, M. S. Diamond, J. Ren, D. I. Stuart, G. R. Screaton, The antigenic anatomy of SARS-CoV-2 receptor binding domain. Cell 184, 2183-2200.e22 (2021). doi:10.1016/j.cell.2021.02.032 Medline

19. F. Amanat, M. Thapa, T. Lei, S. M. S. Ahmed, D. C. Adelsberg, J. M. Carreno, S. Strohmeier, A. J. Schmitz, S. Zafar, J. Q. Zhou, W. Rijnink, H. Alshammary, N. Borcherding, A. G. Reiche, K. Srivastava, E. M. Sordillo, H. van Bakel, J. S. Turner, G. Bajic, V. Simon, A. H. Ellebedy, F. Krammer; Personalized Virology Initiative, The plasmablast response to SARS-CoV-2 mRNA vaccination is dominated by nonneutralizing antibodies that target both the NTD and the RBD. bioRxiv 2021.03.07.21253098 (2021). 10.1101/2021.03.07.21253098 Medline

20. N. Suryadevara, S. Shrihari, P. Gilchuk, L. A. VanBlargan, E. Binshtein, S. J. Zost, R. S. Nargi, R. E. Sutton, E. S. Winkler, E. C. Chen, M. E. Fouch, E. Davidson, B. J. Doranz, R. E. Chen, P.-Y. Shi, R. H. Carnahan, L. B. Thackray, M. S. Diamond, J. E. Crowe Jr., Neutralizing and protective human monoclonal antibodies recognizing the N-terminal domain of the SARS-CoV-2 spike protein. Cell 184, 2316-2331.e15 (2021). doi:10.1016/i.cell.2021.03.029 Medline

21. X. Chi, R. Yan, J. Zhang, G. Zhang, Y. Zhang, M. Hao, Z. Zhang, P. Fan, Y. Dong, Y. Yang, Z. Chen, Y. Guo, J. Zhang, Y. Li, X. Song, Y. Chen, L. Xia, L. Fu, L. Hou, J. Xu, C. Yu, J. Li, Q. Zhou, W. Chen, A neutralizing human antibody binds to the Nterminal domain of the Spike protein of SARS-CoV-2. Science 369, 650-655 (2020). doi:10.1126/science abc6952 Medline

22. A. J. Greaney, T. N. Starr, P. Gilchuk, S. J. Zost, E. Binshtein, A. N. Loes, S. K. Hilton, J. Huddleston, R. Eguia, K. H. D. Crawford, A. S. Dingens, R. S. Nargi, R. E. Sutton, N. Suryadevara, P. W. Rothlauf, Z. Liu, S. P. J. Whelan, R. H. Carnahan, J. E. Crowe Jr., J. D. Bloom, Complete Mapping of Mutations to the SARS-CoV-2 Spike Receptor-Binding Domain that Escape Antibody Recognition. Cell Host Microbe 29, 44-57.e9 (2021). doi:10.1016/i.chom.2020.11.007 Medline

23. T. N. Starr, A. J. Greaney, S. K. Hilton, D. Ellis, K. H. D. Crawford, A. S. Dingens, M. J. Navarro, J. E. Bowen, M. A. Tortorici, A. C. Walls, N. P. King, D. Veesler, J. D. Bloom, Deep Mutational Scanning of SARS-CoV-2 Receptor Binding Domain Reveals Constraints on Folding and ACE2 Binding. Cell 182, 1295-1310.e20 (2020). doi:10.1016/j.cell.2020.08.012 Medline 
24. C. O. Barnes, C. A. Jette, M. E. Abernathy, K. A. Dam, S. R. Esswein, H. B. Gristick, A. G. Malyutin, N. G. Sharaf, K. E. Huey-Tubman, Y. E. Lee, D. F. Robbiani, M. C. Nussenzweig, A. P. West Jr., P. J. Bjorkman, SARS-CoV-2 neutralizing antibody structures inform therapeutic strategies. Nature 588, 682-687 (2020). doi:10.1038/s41586-020-2852-1 Medline

25. S. J. Zost, P. Gilchuk, J. B. Case, E. Binshtein, R. E. Chen, J. P. Nkolola, A. Schäfer J. X. Reidy, A. Trivette, R. S. Nargi, R. E. Sutton, N. Suryadevara, D. R. Martinez, L. E. Williamson, E. C. Chen, T. Jones, S. Day, L. Myers, A. O. Hassan, N. M. Kafai, E. S. Winkler, J. M. Fox, S. Shrihari, B. K. Mueller, J. Meiler, A. Chandrashekar, N. B. Mercado, J. J. Steinhardt, K. Ren, Y.-M. Loo, N. L. Kallewaard, B. T. McCune, S. P. Keeler, M. J. Holtzman, D. H. Barouch, L. E. Gralinski, R. S. Baric, L. B. Thackray, M. S. Diamond, R. H. Carnahan, J. E. Crowe Jr., Potently neutralizing and protective human antibodies against SARS-CoV-2. Nature 584, 443-449 (2020). doi:10.1038/s41586-020-2548-6 Medline

26. L. Liu, P. Wang, M. S. Nair, J. Yu, M. Rapp, Q. Wang, Y. Luo, J. F.-W. Chan, V. Sahi, A. Figueroa, X. V. Guo, G. Cerutti, J. Bimela, J. Gorman, T. Zhou, Z. Chen, K.-Y. Yuen, P. D. Kwong, J. G. Sodroski, M. T. Yin, Z. Sheng, Y. Huang, L. Shapiro, D. D. $\mathrm{Ho}$, Potent neutralizing antibodies against multiple epitopes on SARS-CoV-2 spike. Nature 584, 450-456 (2020). doi:10.1038/s41586-020-2571-7 Medline

27. T. N. Starr, A. J. Greaney, A. Addetia, W. W. Hannon, M. C. Choudhary, A. S. Dingens, J. Z. Li, J. D. Bloom, Prospective mapping of viral mutations that escape antibodies used to treat COVID-19. Science 371, 850-854 (2021). doi:10.1126/science.abf9302 Medline

28. T. N. Starr, A. J. Greaney, A. S. Dingens, J. D. Bloom, Complete map of SARS-CoV2 RBD mutations that escape the monoclonal antibody LY-CoV555 and its cocktail with LY-CoV016. Cell Rep Med 2, 100255 (2021). doi:10.1016/j.xcrm.2021.100255 Medline

29. J. Dong, S. J. Zost, A. J. Greaney, T. N. Starr, A. S. Dingens, E. C. Chen, R. E. Chen, J. B. Case, R. E. Sutton, P. Gilchuk, J. Rodriguez, E. Armstrong, C. Gainza, R. S. Nargi, E. Binshtein, X. Xie, X. Zhan, P.-Y. Shi, J. Logue, S. Weston, M. E. McGrath, M. B. Frieman, T. Brady, K. Tuffy, H. Bright, Y.-M. Loo, P. McTamney, M. Esser, R. H. Carnahan, M. S. Diamond, J. D. Bloom, J. E. Crowe, Genetic and structural basis for recognition of SARS-CoV-2 spike protein by a two-antibody cocktail. bioRxiv 2021.01.27.428529 (2021). Medline

30. N. R. Faria, I. M. Claro, D. Candido, L. A. Moyses Franco, P. S. Andrade, T. M. Coletti, C. A. M. Silva, F. C. Sales, E. R. Manuli, R. S. Aguiar, N. Gaburo, C. da C. Camilo, N. A. Fraiji, M. A. Esashika Crispim, M. do Perpétuo S. S. Carvalho, A. Rambaut, N. Loman, O. G. Pybus, E. C. Sabino, on behalf of CADDE Genomic Network, Genomic characterisation of an emergent SARS-CoV-2 lineage in Manaus: preliminary findings. Virological (2021) (available at https://virological.org/t/genomiccharacterisation-of-an-emergent-sars-cov-2-lineage-in-manaus-preliminaryfindings/586).

31. C. M. Voloch, R. da Silva Francisco Jr., L. G. P. de Almeida, C. C. Cardoso, O. J. Brustolini, A. L. Gerber, A. P. C. Guimarães, D. Mariani, R. M. da Costa, O. C. Ferreira Jr., T. S. Frauches, C. M. B. de Mello, I. C. Leitão, R. M. Galliez, D. S. Faffe, T. M. P. P. Castiñeiras, A. Tanuri, A. T. R. de Vasconcelos; Covid19-UFRJ Workgroup, LNCC Workgroup, Adriana Cony Cavalcanti, Genomic characterization of a novel SARS-CoV-2 lineage from Rio de Janeiro, Brazil. J. Virol. 95, JVI.00119-21 (2021). doi:10.1128/JVI.00119-21 Medline

32. W. Zhang, B. D. Davis, S. S. Chen, J. M. Sincuir Martinez, J. T. Plummer, E. Vail, Emergence of a Novel SARS-CoV-2 Variant in Southern California. JAMA 325, 1324-1326 (2021). doi:10.1001/jama.2021.1612 Medline

33. A. P. West, J. O. Wertheim, J. C. Wang, T. I. Vasylyeva, J. L. Havens, M. A. Chowdhury, E. Gonzalez, C. E. Fang, S. S. Di Lonardo, S. Hughes, J. L. Rakeman, H. H. Lee, C. O. Barnes, P. N. P. Gnanapragasam, Z. Yang, C. Gaebler, M. Caskey, M. C. Nussenzweig, J. R. Keeffe, P. J. Bjorkman, Detection and characterization of the SARS-CoV-2 lineage B.1.526 in New York. bioRxiv 2021.02.14.431043 (2021). Medline

34. M. K. Annavajhala, H. Mohri, J. E. Zucker, Z. Sheng, P. Wang, A. Gomez-Simmonds, D. D. Ho, A.-C. Uhlemann, A novel SARS-CoV-2 variant of concern, B.1.526, identified in New York. medRxiv 2021.02.23.21252259 (2021). 10.1101/2021.02.23.21252259 Medline

35. H. Tegally, E. Wilkinson, M. Giovanetti, A. Iranzadeh, V. Fonseca, J. Giandhari, D. Doolabh, S. Pillay, E. J. San, N. Msomi, K. Mlisana, A. von Gottberg, S. Walaza, M. Allam, A. Ismail, T. Mohale, A. J. Glass, S. Engelbrecht, G. Van Zyl, W. Preiser, F.
Petruccione, A. Sigal, D. Hardie, G. Marais, N.-Y. Hsiao, S. Korsman, M.-A. Davies, L. Tyers, I. Mudau, D. York, C. Maslo, D. Goedhals, S. Abrahams, O. LagudaAkingba, A. Alisoltani-Dehkordi, A. Godzik, C. K. Wibmer, B. T. Sewell, J. Lourenço, L. C. J. Alcantara, S. L. Kosakovsky Pond, S. Weaver, D. Martin, R. J. Lessells, J. N. Bhiman, C. Williamson, T. de Oliveira, Detection of a SARS-CoV-2 variant of concern in South Africa. Nature 592, 438-443 (2021). doi:10.1038/s41586-02103402-9 Medline

36. D. Planas, T. Bruel, L. Grzelak, F. Guivel-Benhassine, I. Staropoli, F. Porrot, C. Planchais, J. Buchrieser, M. M. Rajah, E. Bishop, M. Albert, F. Donati, M. Prot, S. Behillil, V. Enouf, M. Maquart, M. Smati-Lafarge, E. Varon, F. Schortgen, L. Yahyaoui, M. Gonzalez, J. De Sèze, H. Péré, D. Veyer, A. Sève, E. Simon-Lorière, S. Fafi-Kremer, K. Stefic, H. Mouquet, L. Hocqueloux, S. van der Werf, T. Prazuck, O. Schwartz, Sensitivity of infectious SARS-CoV-2 B.1.1.7 and B.1.351 variants to neutralizing antibodies. Nat. Med. 27, 917-924 (2021). doi:10.1038/s41591-02101318-5 Medline

37. M. McCallum, J. Bassi, A. De Marco, A. Chen, A. C. Walls, J. Di lulio, M. Alejandra Tortorici, M.-J. Navarro, C. Silacci-Fregni, C. Saliba, M. Agostini, D. Pinto, K. Culap, S. Bianchi, S. Jaconi, E. Cameroni, J. E. Bowen, S. W. Tiles, M. S. Pizzuto, S. B. Guastalla, G. Bona, A. F. Pellanda, C. Garzoni, W. C. Van Voorhis, L. E. Rosen, G. C. Snell, A. Telenti, H. W. Virgin, L. Piccoli, D. Corti, D. Veesler, SARS-CoV-2 immune evasion by variant B.1.427/B.1.429. bioRxiv 2021.03.31.437925 (2021).

38. A. Kuzmina, Y. Khalaila, O. Voloshin, A. Keren-Naus, L. Boehm-Cohen, Y. Raviv, Y. Shemer-Avni, E. Rosenberg, R. Taube, SARS-CoV-2 spike variants exhibit differential infectivity and neutralization resistance to convalescent or postvaccination sera. Cell Host Microbe 29, 522-528.e2 (2021). doi:10.1016/i.chom.2021.03.008 Medline

39. C. Gaebler, Z. Wang, J. C. C. Lorenzi, F. Muecksch, S. Finkin, M. Tokuyama, A. Cho, M. Jankovic, D. Schaefer-Babajew, T. Y. Oliveira, M. Cipolla, C. Viant, C. O. Barnes, Y. Bram, G. Breton, T. Hägglöf, P. Mendoza, A. Hurley, M. Turroja, K. Gordon, K. G. Millard, V. Ramos, F. Schmidt, Y. Weisblum, D. Jha, M. Tankelevich, G. MartinezDelgado, J. Yee, R. Patel, J. Dizon, C. Unson-O'Brien, I. Shimeliovich, D. F. Robbiani, Z. Zhao, A. Gazumyan, R. E. Schwartz, T. Hatziioannou, P. J. Bjorkman, S. Mehandru, P. D. Bieniasz, M. Caskey, M. C. Nussenzweig, Evolution of antibody immunity to SARS-CoV-2. Nature 591, 639-644 (2021). doi:10.1038/s41586021-03207-w Medline

40. F. Muecksch, Y. Weisblum, C. O. Barnes, F. Schmidt, D. Schaefer-Babajew, J. C. C. Lorenzi, A. I. Flyak, A. T. DeLaitsch, K. E. Huey-Tubman, S. Hou, C. A. Schiffer, C. Gaebler, Z. Wang, J. Da Silva, D. Poston, S. Finkin, A. Cho, M. Cipolla, T. Y. Oliveira, K. G. Millard, V. Ramos, A. Gazumyan, M. Rutkowska, M. Caskey, M. C. Nussenzweig, P. J. Bjorkman, T. Hatziioannou, P. D. Bieniasz, Development of potency, breadth and resilience to viral escape mutations in SARS-CoV-2 neutralizing antibodies. bioRxiv 2021.03.07.434227 (2021). Medline

41. L. Dai, G. F. Gao, Viral targets for vaccines against COVID-19. Nat. Rev. Immunol. 21, 73-82 (2021). doi:10.1038/s41577-020-00480-0 Medline

42. N. Pardi, M. J. Hogan, F. W. Porter, D. Weissman, mRNA vaccines - a new era in vaccinology. Nat. Rev. Drug Discov. 17, 261-279 (2018) doi:10.1038/nrd.2017.243 Medline

43. K. Röltgen, S. C. A. Nielsen, P. S. Arunachalam, F. Yang, R. A. Hoh, O. F. Wirz, A. S. Lee, F. Gao, V. Mallajosyula, C. Li, E. Haraguchi, M. J. Shoura, J. L. Wilbur, J. N. Wohlstadter, M. M. Davis, B. A. Pinsky, G. B. Sigal, B. Pulendran, K. C. Nadeau, S. D. Boyd, mRNA vaccination compared to infection elicits an IgG-predominant response with greater SARS-CoV-2 specificity and similar decrease in variant spike recognition. medRxiv 2021.04.05.21254952 (2021). Medline

44. S. R. Hamilton, P. Bobrowicz, B. Bobrowicz, R. C. Davidson, H. Li, T. Mitchell, J. H. Nett, S. Rausch, T. A. Stadheim, H. Wischnewski, S. Wildt, T. U. Gerngross, Production of complex human glycoproteins in yeast. Science 301, 1244-1246 (2003). doi:10.1126/science.1088166 Medline

45. J. Otwinowski, D. M. McCandlish, J. B. Plotkin, Inferring the shape of global epistasis. Proc. Natl. Acad. Sci. U.S.A. 115, E7550-E7558 (2018) doi:10.1073/pnas.1804015115 Medline

46. K. H. D. Crawford, R. Eguia, A. S. Dingens, A. N. Loes, K. D. Malone, C. R. Wolf, H. Y. Chu, M. A. Tortorici, D. Veesler, M. Murphy, D. Pettie, N. P. King, A. B. Balazs, J. D. Bloom, Protocol and Reagents for Pseudotyping Lentiviral Particles with SARSCoV-2 Spike Protein for Neutralization Assays. Viruses 12, 513 (2020). doi:10.3390/v12050513 Medline 
47. B. Korber, W. M. Fischer, S. Gnanakaran, H. Yoon, J. Theiler, W. Abfalterer, N. Hengartner, E. E. Giorgi, T. Bhattacharya, B. Foley, K. M. Hastie, M. D. Parker, D. G. Partridge, C. M. Evans, T. M. Freeman, T. I. de Silva, C. McDanal, L. G. Perez, H. Tang, A. Moon-Walker, S. P. Whelan, C. C. LaBranche, E. O. Saphire, D. C. Montefiori, A. Angyal, R. L. Brown, L. Carrilero, L. R. Green, D. C. Groves, K. J. Johnson, A. J. Keeley, B. B. Lindsey, P. J. Parsons, M. Raza, S. Rowland-Jones, N. Smith, R. M. Tucker, D. Wang, M. D. Wyles; Sheffield COVID-19 Genomics Group, Tracking Changes in SARS-CoV-2 Spike: Evidence that D614G Increases Infectivity of the COVID-19 Virus. Cell 182, 812-827.e19 (2020). doi:10.1016/i.cell.2020.06.043 Medline

48. A. S. Dingens, K. H. D. Crawford, A. Adler, S. L. Steele, K. Lacombe, R. Eguia, F. Amanat, A. C. Walls, C. R. Wolf, M. Murphy, D. Pettie, L. Carter, X. Qin, N. P. King, D. Veesler, F. Krammer, J. A. Dickerson, H. Y. Chu, J. A. Englund, J. D. Bloom, Serological identification of SARS-CoV-2 infections among children visiting a hospital during the initial Seattle outbreak. Nat. Commun. 11, 4378 (2020). doi:10.1038/s41467-020-18178-1 Medline

49. J. Hansen, A. Baum, K. E. Pascal, V. Russo, S. Giordano, E. Wloga, B. O. Fulton, Y. Yan, K. Koon, K. Patel, K. M. Chung, A. Hermann, E. Ullman, J. Cruz, A. Rafique, T. Huang, J. Fairhurst, C. Libertiny, M. Malbec, W.-Y. Lee, R. Welsh, G. Farr, S. Pennington, D. Deshpande, J. Cheng, A. Watty, P. Bouffard, R. Babb, N. Levenkova, C. Chen, B. Zhang, A. Romero Hernandez, K. Saotome, Y. Zhou, M. Franklin, S. Sivapalasingam, D. C. Lye, S. Weston, J. Logue, R. Haupt, M. Frieman, G. Chen, W. Olson, A. J. Murphy, N. Stahl, G. D. Yancopoulos, C. A. Kyratsous, Studies in humanized mice and convalescent humans yield a SARS-CoV-2 antibody cocktail. Science 369, 1010-1014 (2020). doi:10.1126/science.abd0827 Medline

50. J. Lan, J. Ge, J. Yu, S. Shan, H. Zhou, S. Fan, Q. Zhang, X. Shi, Q. Wang, L. Zhang, $X$. Wang, Structure of the SARS-CoV-2 spike receptor-binding domain bound to the ACE2 receptor. Nature 581, 215-220 (2020). doi:10.1038/s41586-020-21805 Medline

51. S. Hilton, J. Huddleston, A. Black, K. North, A. Dingens, T. Bedford, J. Bloom, dmsview: Interactive visualization tool for deep mutational scanning data. J. Open Source Softw. 5, 2353 (2020). doi:10.21105/joss.02353

Acknowledgments: We thank Cathy Lin for administrative support; Dolores Covarrubias, Andy Marty, and the Genomics and Flow Cytometry core facilities at the Fred Hutchinson Cancer Research Center for experimental support. We thank Lisa Jackson (Kaiser Permanente), Chris Roberts, Catherine Luke, and Rebecca Lampley (National Institute of Allergy and Infectious Diseases (NIAID), National Institutes of Health (NIH)) for assistance with obtaining the mRNA-1273 phase 1 trial vaccine samples. We also thank all research participants and study staff of the Hospitalized or Ambulatory Adults with Respiratory Viral Infections (HAARVI) study. Funding: This study was funded by the NIAID, NIH (R01Al141707 and R01Al127893 to JDB, T32AI083203 to AJG, and F30Al149928 to KDHC); the Gates Foundation (INV-004949 to JDB and INV-016575 to HYC); an Emergent Ventures Award (to HYC); the National Institutes of Health Office of Research Infrastructure Programs S100D028685 (to the Scientific Computing Infrastructure at the Fred Hutchinson Cancer Research Center); and the Howard Hughes Medical Institute (to JDB). TNS is a Howard Hughes Medical Institute Fellow of the Damon Runyon Cancer Research Foundation (DRG-2381-19). The mRNA-1273 phase 1 study was sponsored and primarily funded by the NIAID, $\mathrm{NIH}$. This trial has been funded in part with federal funds from the NIAID under grant awards UM1Al148373, to Kaiser Washington; UM1Al148576, UM1Al148684, and NIH P51 OD011132, to Emory University; NIH AID AI149644, and contract award HHSN272201500002C, to Emmes. Funding for the manufacture of mRNA-1273 phase 1 material was provided by the Coalition for Epidemic Preparedness Innovation. Author contributions: AJG and JDB conceptualized and designed the study. AJG and TNS developed the yeast-display deep mutational scanning antibody-escape mapping method. KHDC developed the spike-pseudotyped lentiviral system and neutralization assays. AJG performed the serum-escape mapping. KDM assisted with serum-escape mapping; ANL cloned spike point mutants and generated pseudotyped lentiviral particles. ANL, $A J G$, and LEG performed pseudotyped neutralization assays. AJG and JDB wrote the code and performed the formal analysis. HYC provided the convalescent plasma and serum samples. AJG and JDB wrote the original draft and all authors reviewed and edited the manuscript. Competing interests: Subsequent to completion and submission of the initial version of this study, JDB began consulting for Moderna on viral evolution and epidemiology. JDB and KHD have the potential to receive a share of IP revenue as an inventor on a Fred Hutchinson Cancer Research Center-optioned technology/patent (application W02020006494) related to deep mutational scanning of viral proteins. HYC is a consultant for Merck, Pfizer, Ellume, and the Bill and Melinda Gates Foundation and has received support from Cepheid and Sanofi-Pasteur. The other authors declare no competing interests. Data and materials availability: All data associated with this study are in the paper or supplementary materials. The SARS-CoV-2 RBD mutant libraries (\#1000000172) and unmutated parental plasmid (\#166782) are available on Addgene. The plasmid encoding the SARSCoV-2 spike gene used to generate pseudotyped lentiviral particles, HDM_Spikedelta21_D614G, is available from Addgene (\#158762) and BEI Resources (NR-53765). The complete code for the full computational data analysis pipeline of the mapping experiments is available at https://github.com/ibloomlab/SARS-CoV-2-RBD MAP Moderna, and archived in the Zenodo code repository (doi 10.5281/zenodo.4741330) (52). The escape fraction measured for each mutation in data file $\mathrm{S} 2$ and also at https://github.com/jbloomlab/SARS-CoV-2RBD MAP Moderna/blob/main/results/supp data/Moderna convalescent all raw_data.csv. All raw sequencing data are available on the NCBI Short Read Archive at BioProject PRJNA639956, BioSample SAMN18683769. The neutralization titers of vaccine- and infection-elicited sera against the tested RBD point mutants is in data file $\mathrm{S} 3$ and at https://github.com/ibloomlab/SARS-CoV-2RBD MAP Moderna/blob/main/experimental data/results/mutant neuts res ults/fitparams.Csv. This work is licensed under a Creative Commons Attribution 4.0 International (CC BY 4.0) license, which permits unrestricted use, distribution, and reproduction in any medium, provided the original work is properly cited. To view a copy of this license, visit https://creativecommons.org/licenses/by/4.0/. This license does not apply to figures/photos/artwork or other content included in the article that is credited to a third party; obtain authorization from the rights holder before using this material.

Submitted 14 April 2021

Accepted 2 June 2021

Published First Release 8 June 2021

10.1126/scitransImed.abi9915 
A

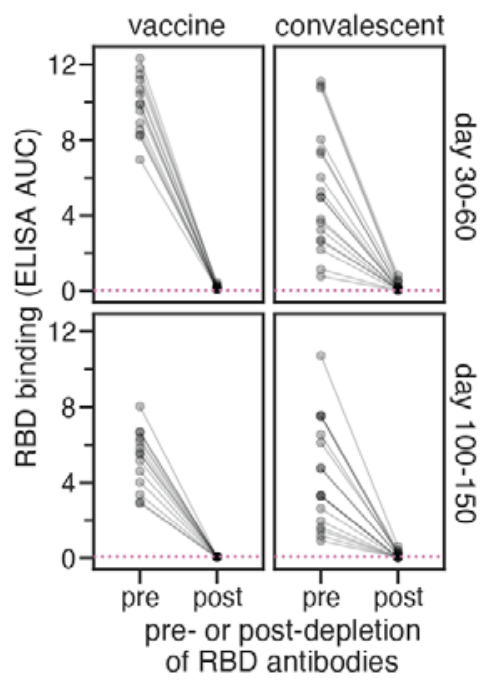

B

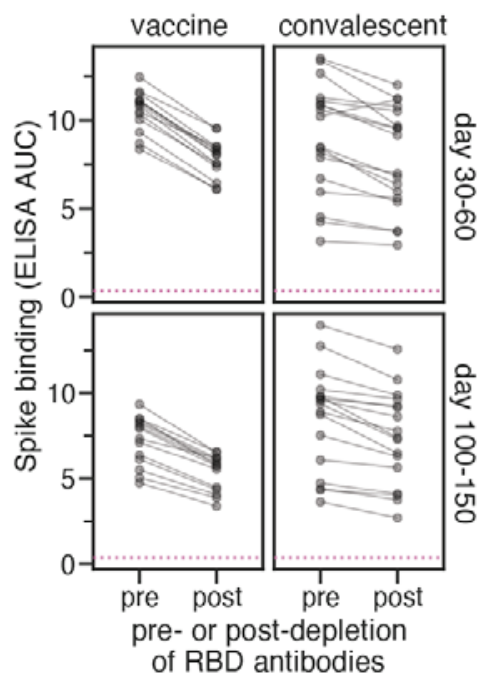

of RBD antibodies

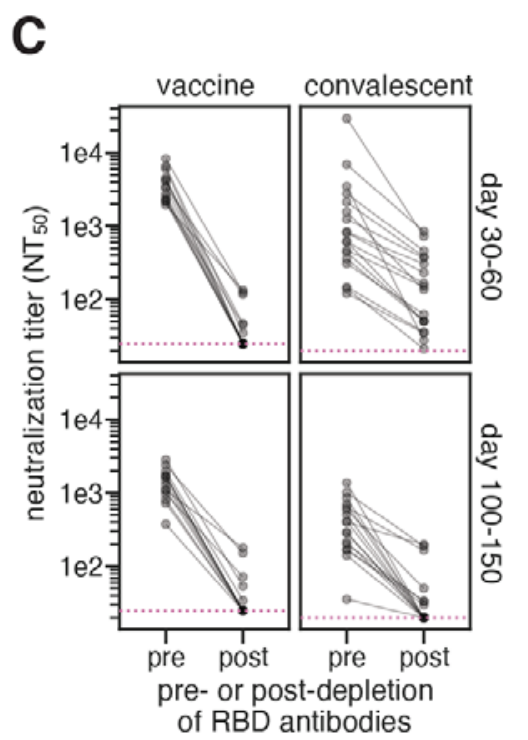

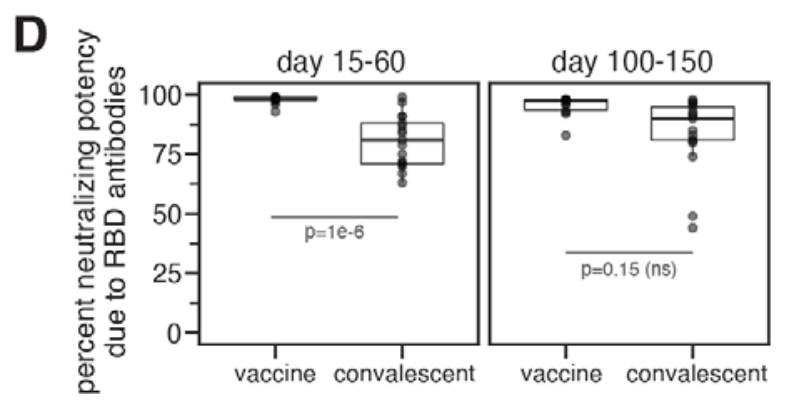

Fig. 1. RBD-binding antibodies are responsible for most neutralizing activity of mRNA-1273 vaccine-elicited sera. (A) Binding of serum antibodies to SARS-CoV-2 RBD, as measured by ELISA area-under-the-curve (AUC), for vaccine-elicited sera and convalescent plasma before and after depletion of RBD-binding antibodies. The dashed pink line indicates binding of pre-pandemic sera. (B) Binding of serum antibodies to the full spike ectodomain. The $y$-axis scale units in $(A)$ and $(B)$ are not comparable between samples from vaccinated and convalescent individuals due to different dilution factors (beginning at 1:500 for vaccine sera and 1:100 for convalescent plasma samples). (C) Neutralization titer ( $\mathrm{NT}_{50}$ ) of vaccine-elicited sera and convalescent plasma samples before and after depletion of RBD-binding antibodies. The limit of detection is shown as a dashed horizontal pink line. (D) Percent of neutralizing activity of vaccine-elicited sera and convalescent plasma samples due to RBD-binding antibodies. P-values are from a log-rank test accounting for censoring. $n=17$ for each time point for convalescent plasma samples, and $n=14$ for each time point for vaccine sera. ns, not significant. All measurements of convalescent plasma binding and neutralization were previously reported in (15). 
A

occluded in the "down" conformation

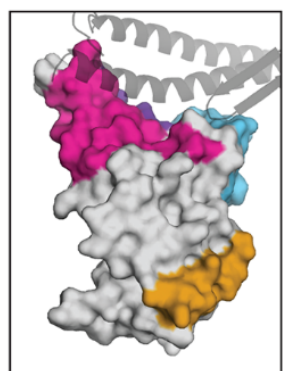

class 1 epitope

class 2 epitope

C
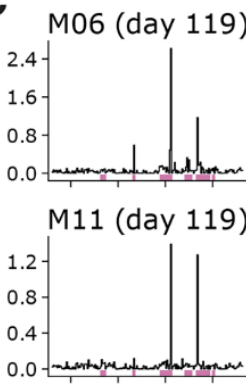

M05 (day 119)

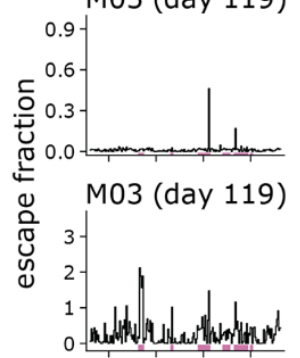

M12 (day 119)

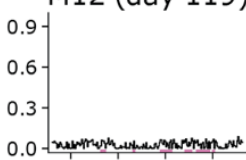

M14 (day 119)

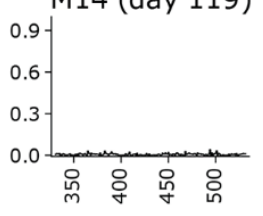

exposed in the "up" and "down" conformations

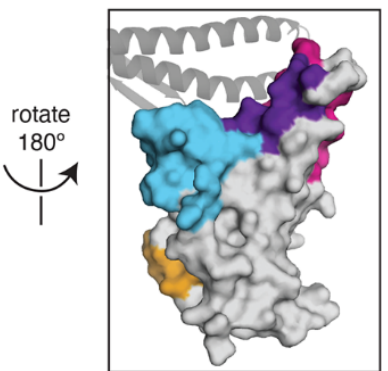

class 3 epitope

class 4 epitope
B

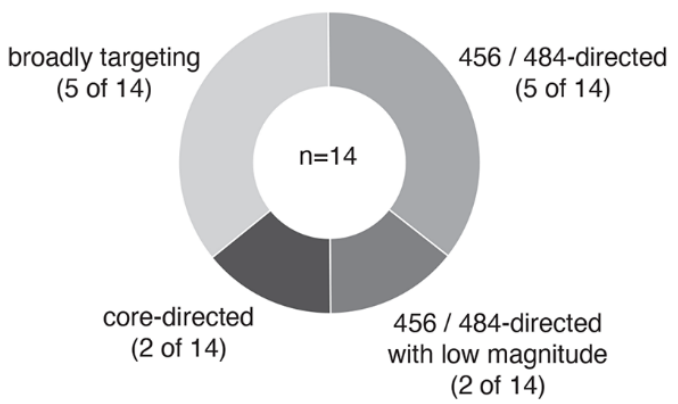

456 / 484-directed 5 out of 14 samples
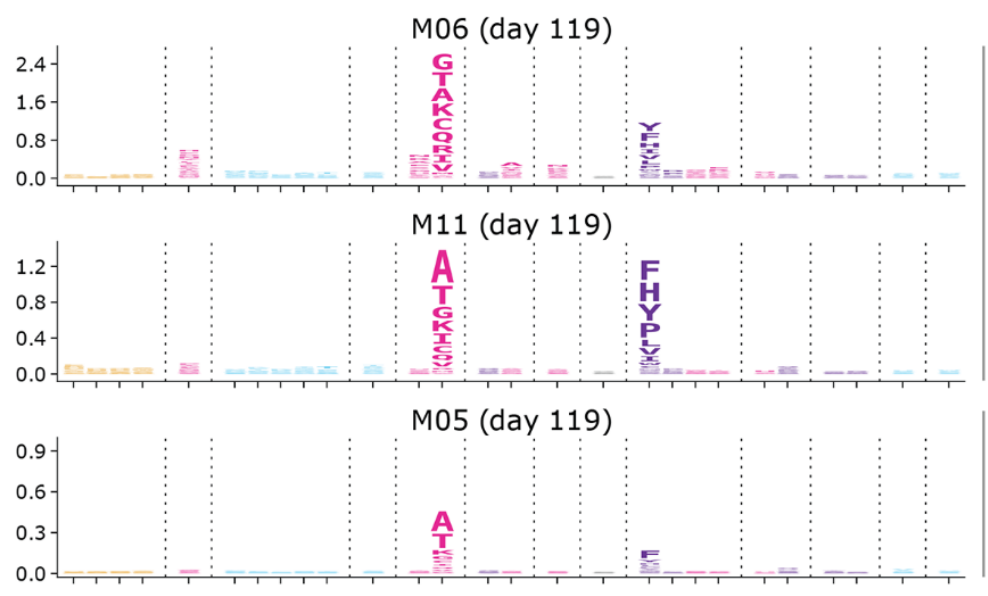

456 / 484-directed with low magnitude 2 out of 14 samples

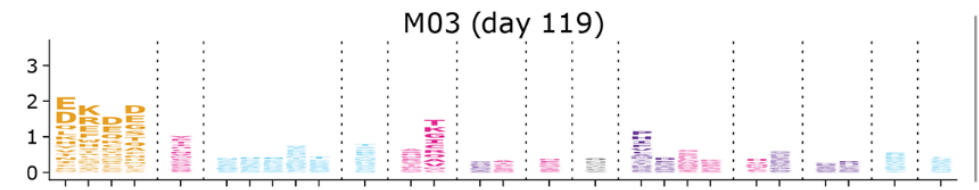

core (class 4 epitope) directed

2 out of 14 samples
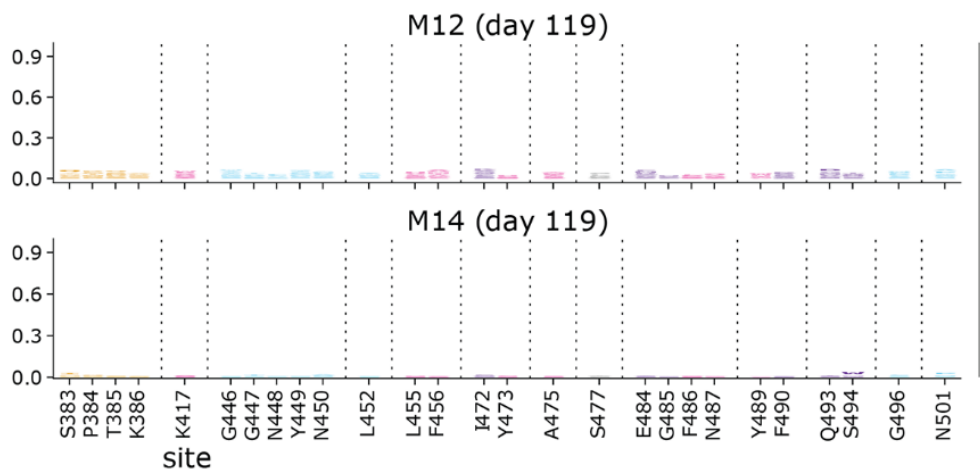

broadly targeting 5 out of 14 samples

Fig. 2. Complete maps of RBD mutations that reduce binding by sera collected 119 days post-vaccination with the 250 $\mu \mathrm{g}$ dose of the mRNA-1273 vaccine. (A) The epitopes of four major classes (24) of RBD-binding antibodies are colored on the RBD surface (PDB 6MOJ). ACE2 is shown as a gray ribbon diagram. (B) Number of sera that fell into each of the four major categories of binding-escape maps as categorized by subjective visual inspection. (C) Escape maps for six representative sera are shown. The line plots at left indicate the sum of effects of all mutations at each RBD site on serum antibody binding, with larger values indicating more escape. The logo plots at right show key sites (highlighted in purple on the line plot $x$-axes). The height of each letter is that mutation's escape fraction; larger letters indicate a greater reduction in binding. Escape fractions are not strictly comparable between samples due to the use of sample-specific FACS selection gates-therefore, for each sample, the $y$-axis is scaled independently. RBD sites are colored by epitope as in (A). The escape fractions were correlated between independent libraries, and we report the average of duplicate measurements throughout. Interactive versions of logo plots and structural visualizations are at https://jbloomlab.github.io/SARS-CoV2-RBD MAP Moderna/. 

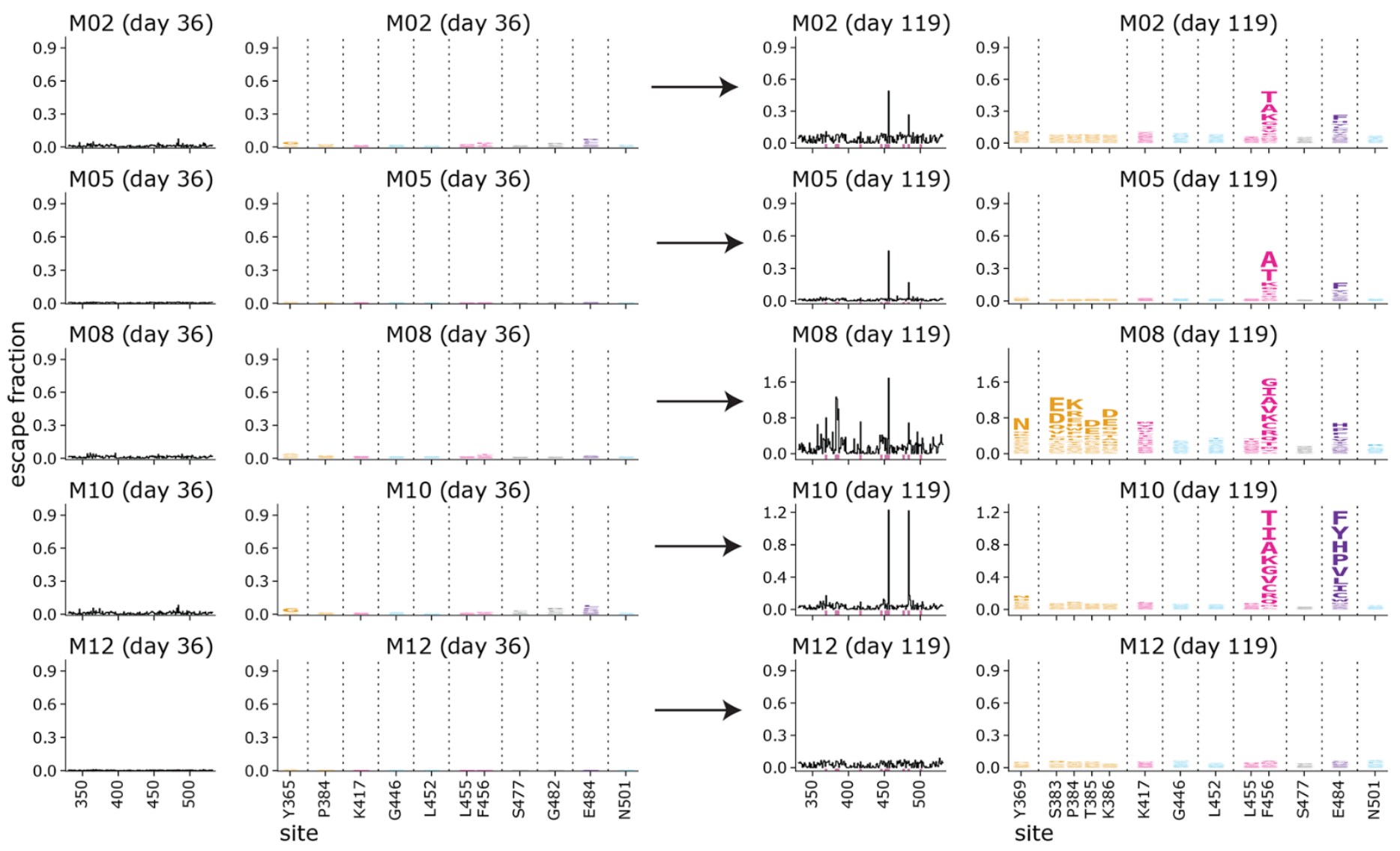

Fig. 3. Comparison of escape maps for sera collected at days 36 and 119 post-vaccination shows that the RBD-binding response becomes more focused over time. (A and B) Escape maps for sera at day 36 (A) and day 119 (B) from 5 individuals who received the $250 \mu \mathrm{g}$ vaccine dose are shown. The day 36 maps are all relatively flat, indicating no RBD mutation has a large effect on serum antibody binding. By day 119, the maps are often more focused on sites 456 and 484 . The $y$-axis is scaled separately for each serum sample. Interactive versions are at https://ibloomlab.github.io/SARS-CoV-2-RBD_MAP ModernaL. 
A

A vaccine (day $36, n=5$ )

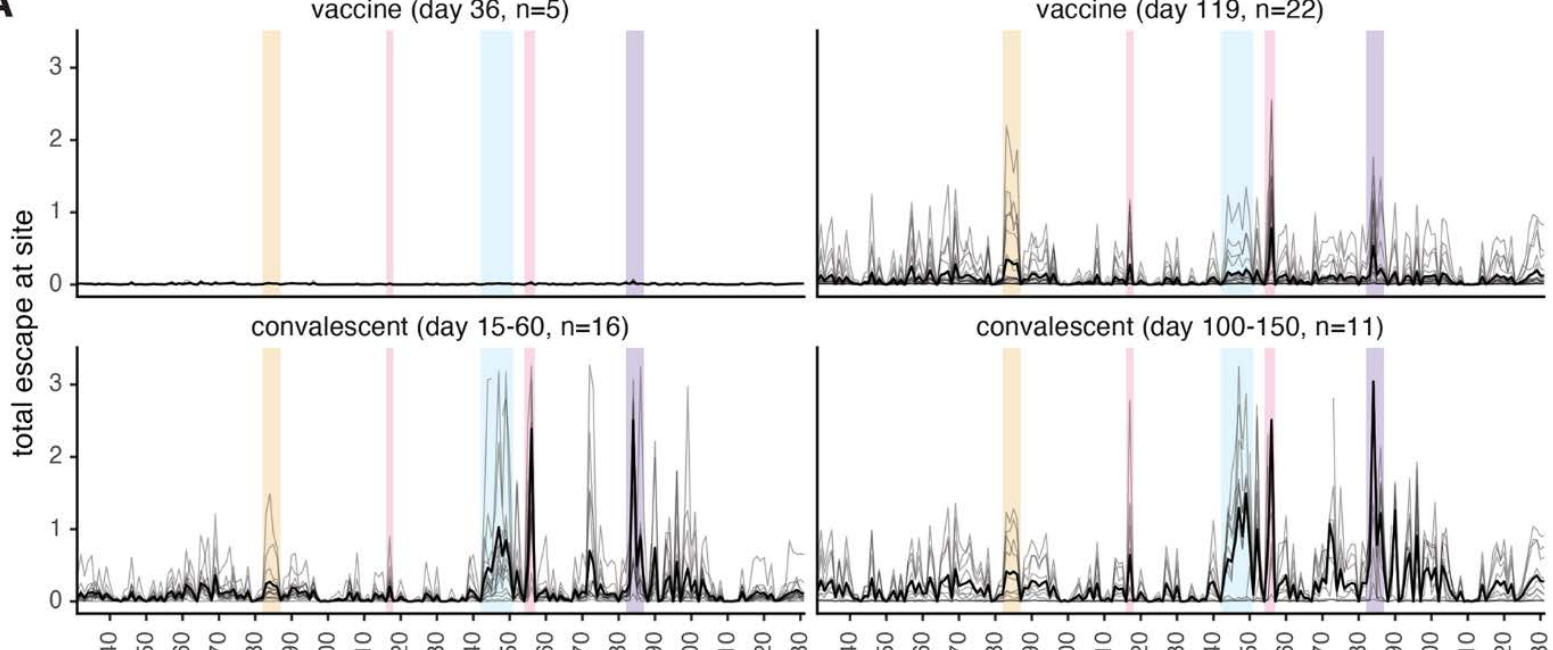

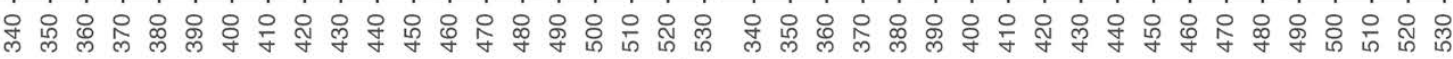

B

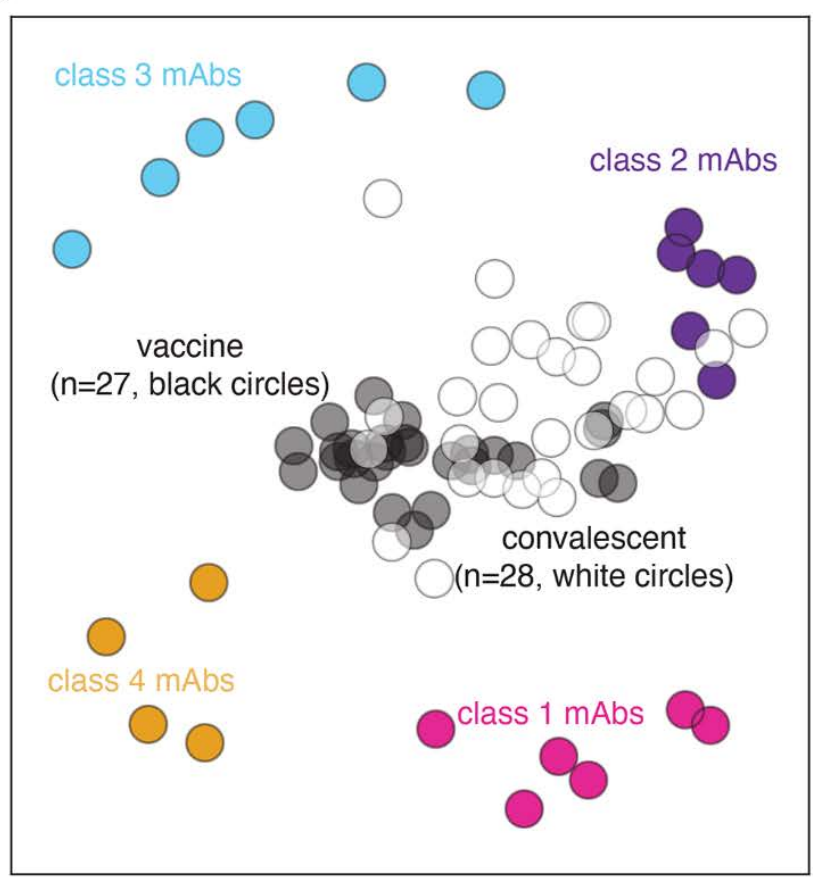

C

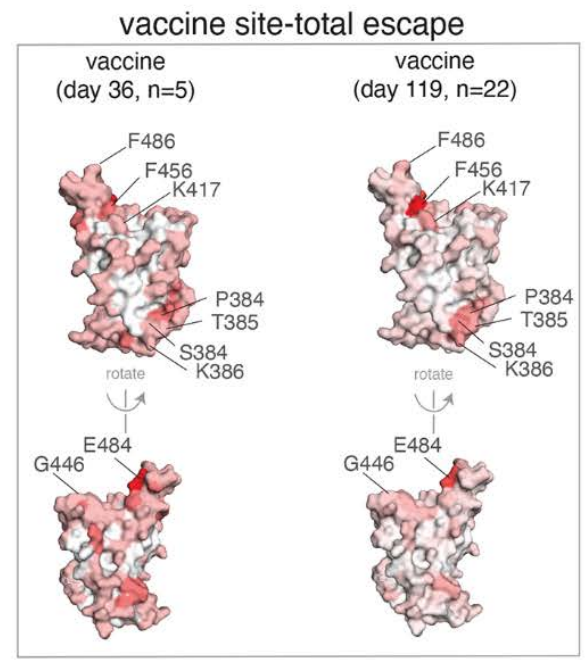

convalescent site-total escape

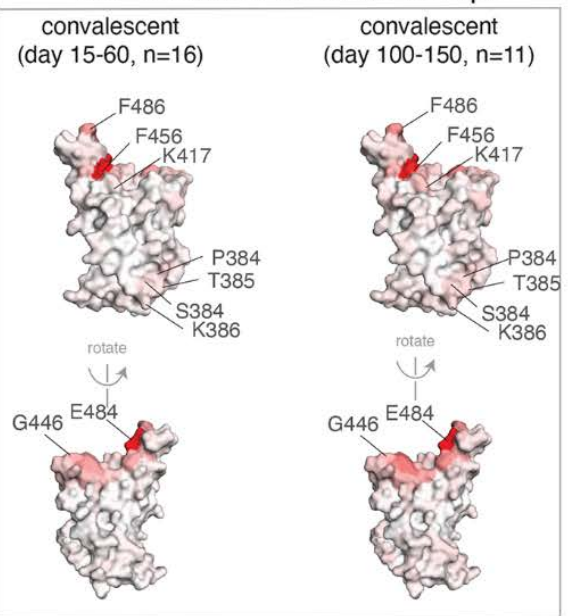


Fig. 4. The binding of vaccine-elicited polyclonal antibodies is more broadly distributed across the RBD than the binding of infection-elicited antibodies. (A) Escape from RBD-binding antibodies at each site in the RBD was mapped for vaccine sera or convalescent plasma samples collected at early or late time points. Thin gray lines show individual serum or plasma samples, and the thick black line shows the mean (number of samples is indicated in the plot titles). Key sites within the epitopes of each major RBD antibody class are highlighted with the colors defined in Fig. 2A and in panel (B). (B) Relationships among escape maps of vaccine sera, convalescent plasma samples, and monoclonal antibodies visualized with a multidimensional scaling projection. Vaccine sera include both doses and time points. Convalescent plasma samples include all time points. (C) Total binding escape at each site mapped onto the RBD surface after averaging across all serum or plasma in each group. The RBD surface coloring is scaled from white to red, with white indicating no escape, and red indicating the site with the greatest escape. The color scaling spans the full range of white to red for each serum or plasma group, so a quantitative scale is not comparable across groups. Escape maps for monoclonal antibodies previously described in (16, 22, 27-29), and convalescent plasma samples in $(15,16)$. An interactive version of panel (B) where you can mouse over points for details is at https://jbloomlab.github.io/SARS-CoV-2-RBD_MAP Moderna/mds.html. 
A
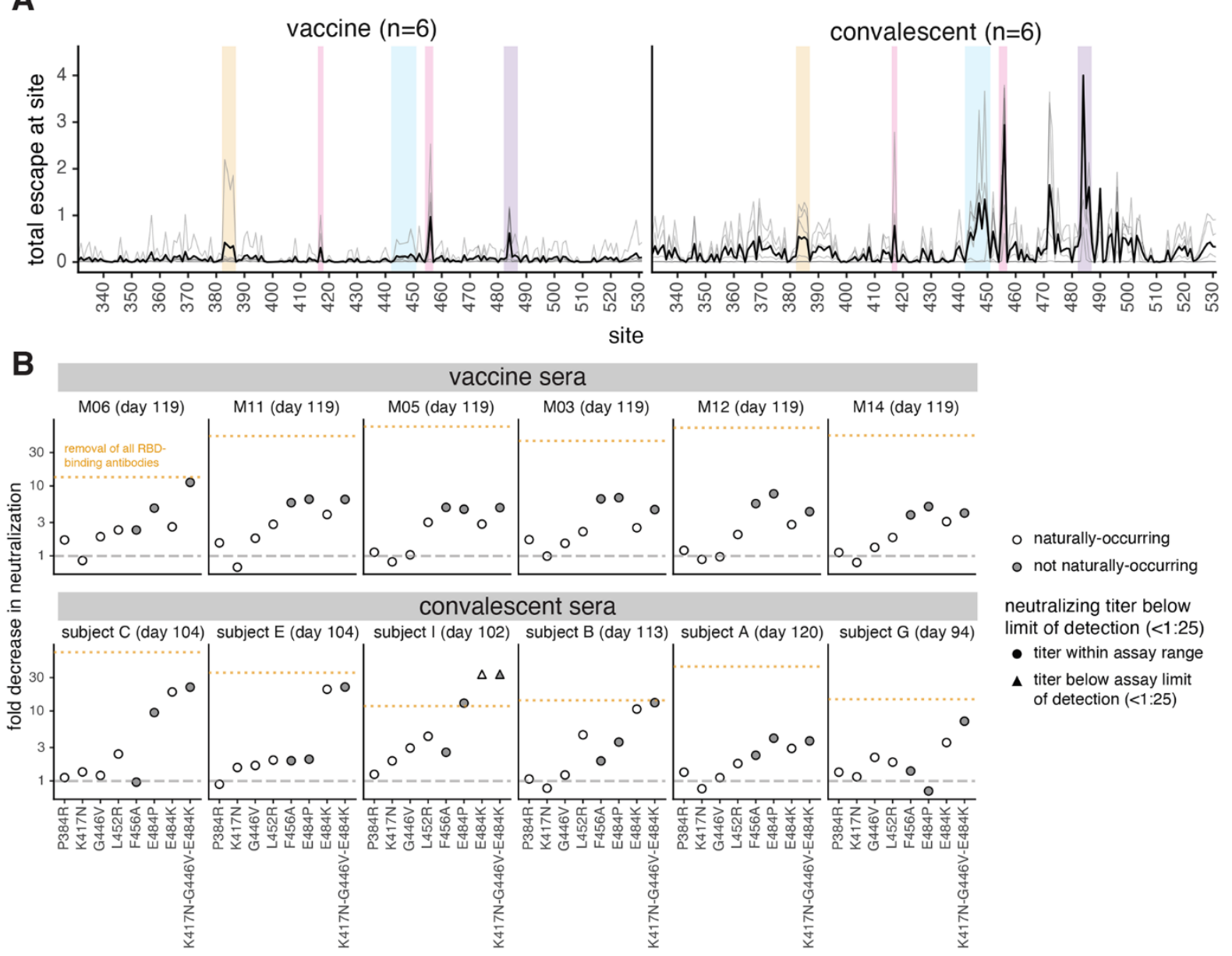

$\circ$ naturally-occurring
$\circ$ not naturally-occurring

neutralizing titer below limit of detection $(<1: 25)$

- titer within assay range

A titer below assay limit of detection $(<1: 25)$

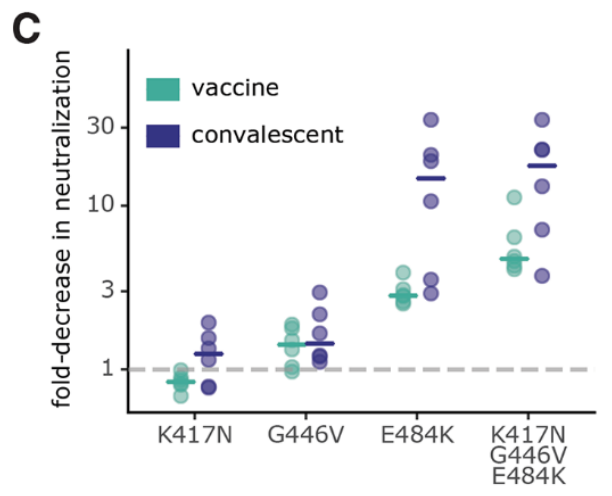

D

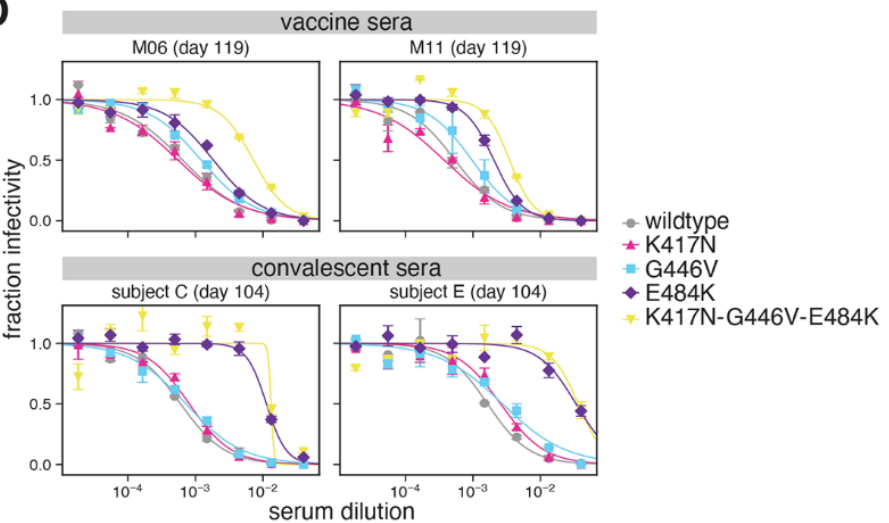

Fig. 5. Effects of RBD mutations on neutralization by day 100-150 sera from vaccinated and convalescent individuals. (A) Total binding escape at each RBD site is shown for the samples from vaccinated $(n=6)$ or convalescent $(n=6)$ individuals tested in neutralization assays. The thin gray lines show individual samples, and the dark black line shows the mean. Key sites within each epitope are highlighted using the same color scheme as in Fig. 2A. (B) Neutralization of G614 spike-pseudotyped lentiviral particles with the indicated RBD mutations, shown as the fold-decrease in NT 50 compared to G614 spike with no additional mutations. Mutations that have been observed in human SARS-CoV-2 isolates are colored in white, and non-naturally-occurring mutations in gray. The orange dashed line represents the effect of depleting all RBDbinding antibodies. (C) The fold decrease in neutralization titer caused by individual mutations in each of the three major neutralizing epitopes of the RBD: K417 in the class 1 epitope, E484K in the class 2 epitope, and G446V in the class 3 epitope. The combination of all three mutations is also shown. Horizontal lines represent the median. In (B) and (C), the dashed gray line indicates no change in neutralization relative to unmutated spike. (D) Representative neutralization curves from two vaccine and two convalescent samples against the triple mutant and its composite single mutations. 